UNIVERSITY OF TARTU

FACULTY OF SCIENCE AND TECHNOLOGY

Insitute of Physics

Kaarel Kaldvee

\title{
APPROACHES TO CONTACTLESS OPTICAL THERMOMETER IN THE NIR SPECTRAL RANGE BASED ON Nd ${ }^{3+}$ DOPED CRYSTALLINE NANOPARTICLES
}

Physics Master's thesis (30 ECTS)

Supervisors:

Dr. hab., Ph.D. Yury Orlovskiy Ph.D. Ilmo Sildos 


\title{
Approaches to contactless optical thermometer in the NIR spectral range based on $\mathrm{Nd}^{3+}$ doped crystalline nanoparticles
}

\author{
Master's thesis \\ Kaarel Kaldvee
}

\begin{abstract}
The fluorescence kinetics and spectral intensity ratio (FIR) methods for contactless optical temperature measurement in the NIR spectral range with $\mathrm{Nd}^{3+}$ doped YAG micro- and $\mathrm{YPO}_{4}$ nanocrystals are developed, tested and the problems are revealed. The requirements for optical temperature RE doped crystalline nanoparticles sensors working in NIR spectral range are formulated.
\end{abstract}

Keywords: Fluorescent thermometer, NIR, $\mathrm{Nd}^{3+}$, YAG micro- and $\mathrm{YPO}_{4}$ nanocrystals, kinetic and FIR methods

CERCS: P260 Condensed matter: electronic structure, electrical, magnetic and optical properties, supraconductors, magnetic resonance, relaxation, spectroscopy

\section{Meetodid kontaktivabaks optiliseks temperatuuri mõõtmiseks NIR spektraalvahemikus kasutades $\mathrm{Nd}^{3+}$ ioonidega dopeeritud kristalseid nanoosakesi}

Magistritöö

Kaarel Kaldvee

Lühikokkuvõte. Töös tutvustatakse kahte kontaktivaba optilist temperatuuri mõõtmise meetodit, mis põhinevad fluorestsentsi kineetika ja spektraalse intensiivsuste suhte (FIR fluorescence intensity ratio) mõõtmisel. Meetodeid katsetatakse $\mathrm{Nd}^{3+}$ ioonidega dopeeritud YAG mikro- ja $\mathrm{YPO}_{4}$ nanokristallide peal. Tulemuste põhjal formuleeritakse nõuded haruldaste muldmetallide ioonidega dopeeritud kristallilistele materjalidele töötamaks optiliste temperatuurisensoritena lähiinfrapuna piirkonnas.

Märksõnad: fluorestsentstermomeeter, NIR, $\mathrm{Nd}^{3+}$, YAG mikro- and $\mathrm{YPO}_{4}$ nanokristallid, fluorestsentsi kineetika ja FIR meetodid

CERCS: P260 Tahke aine: elektrooniline struktuur, elektrilised, magneetilised ja optilised omadused, ülijuhtivus, magnetresonants, spektroskoopia 


\section{Contents}

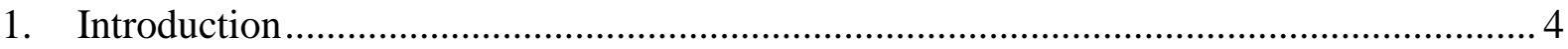

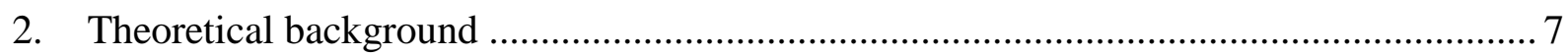

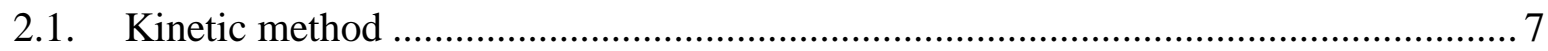

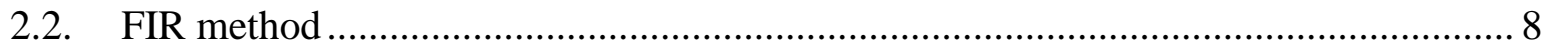

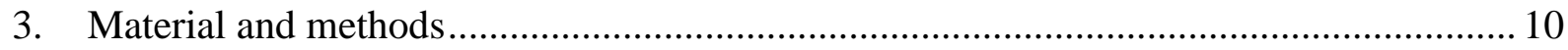

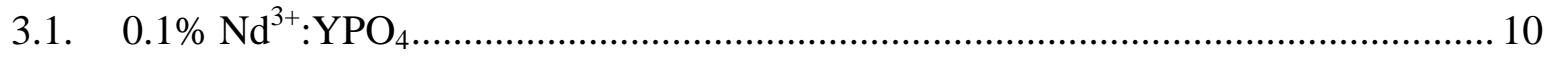

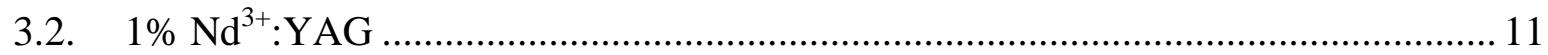

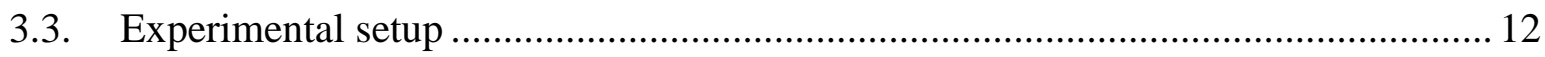

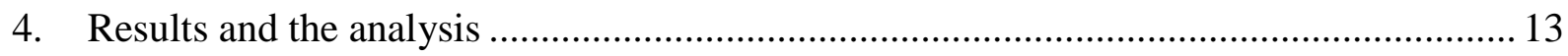

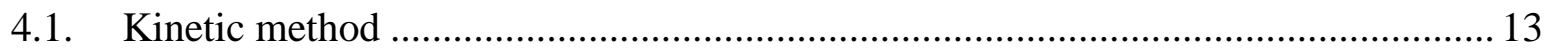

4.2. The Florescence Intensity Ratio (FIR) method ..................................................... 22

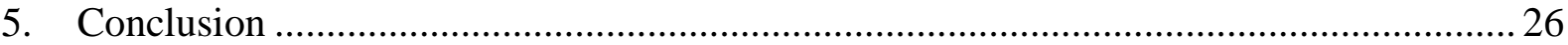

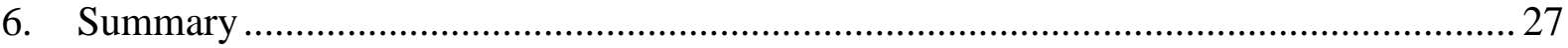

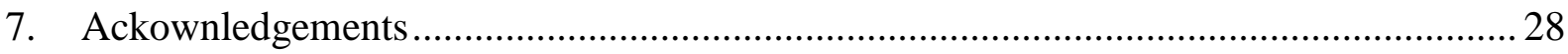

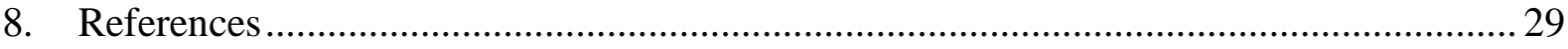




\section{Introduction}

Temperature plays a high role in everyday life and that is why it is measured and monitored that much. There are many methods to measure temperature, which work great in most of the situatuions, but are not so well suited for some of the modern science fields, such as nanotechnology and biomedicine. In this work the possibilities of using of contactless optical thermometry with the application to control the temperature in laser hyperthermia treatment of cancer cells is discussed. Especially interesting for medical applications is the near infrared (NIR) spectral range $(650-1300 \mathrm{~nm})$ in which lies the of biological tissue transparency windows. There are several commercially available NIR laser diodes and tunable Ti- Sapphire laser, which can be used for fluorescence excitation in first biological window $(750-950 \mathrm{~nm})$ [1]. Modern NIR detectors, cameras and photomultiplier tubes (PMTs) have high enough sensitivity to acquire the fluorescence spectra and the kinetics within a reasonable time (several seconds) necessary for monitoring in real time the process of laser heating of the tumors. The fluorescence methods of temperature measurement have been developed since the end of the XX century in connection with optical fiber sensors [2]. The rare-earth (RE) doped optical nanocrystals with their long fluorescence lifetimes (from dozens of microseconds to milliseconds), and narrow fluorescence spectral lines are the most attractive candidates for the temperature sensors.

There are some papers that have dealt with temperature control with FIR method using fluorescence of $\mathrm{Nd}^{3+}$ doped nanoparticles in NIR spectral range during hyperthermia treatment [3-6]. However, the reliability of the methods for temperature control requires more detailed theoretical analysis and further experimental approbation.

There are two main fluorescence-based methods with justified theoretical background for contactless temperature measurement. These are kinetic method and spectral fluorescence intensity ratio (FIR) method. Both of them are based on the three energy level model of luminescent ion [7]. The first one is based on measurement of fluorescence kinetics depending on temperature after excitation with the laser pulse much shorter than the fluorescence decay time $\tau$. Usually the fluorescence decay of two closely spaced levels 1 and 2 separated by energy gap $\Delta E$ is measured. The excitation is relaxing to the ground state 0 after fast redistribution of population according to Boltzmann law in a time much shorter than spontaneous decay time (Fig. 1). As a result the kinetics is always exponential with the decay time depending on temperature. It is important that lifetimes of levels 1 and 2 must be significantly different and almost independent on temperature. The former can be realized, 
because the line strengths $S_{\text {ed }}$ of the optical transitions between crystal-field (C.F.) levels belonging to the different manifolds can be strongly different. Exact ab initio calculation of the line strengths is hardly possible and in any case requires experimental verification. If the overall spontaneous emission rates of C.F. level 1 and 2 are strongly different the sensor can be realized.

The second method is based on the temperature dependence of the fluorescence intensity ratio (FIR) measured for two spectral lines of the transitions from levels 1 and 2 to level 0.

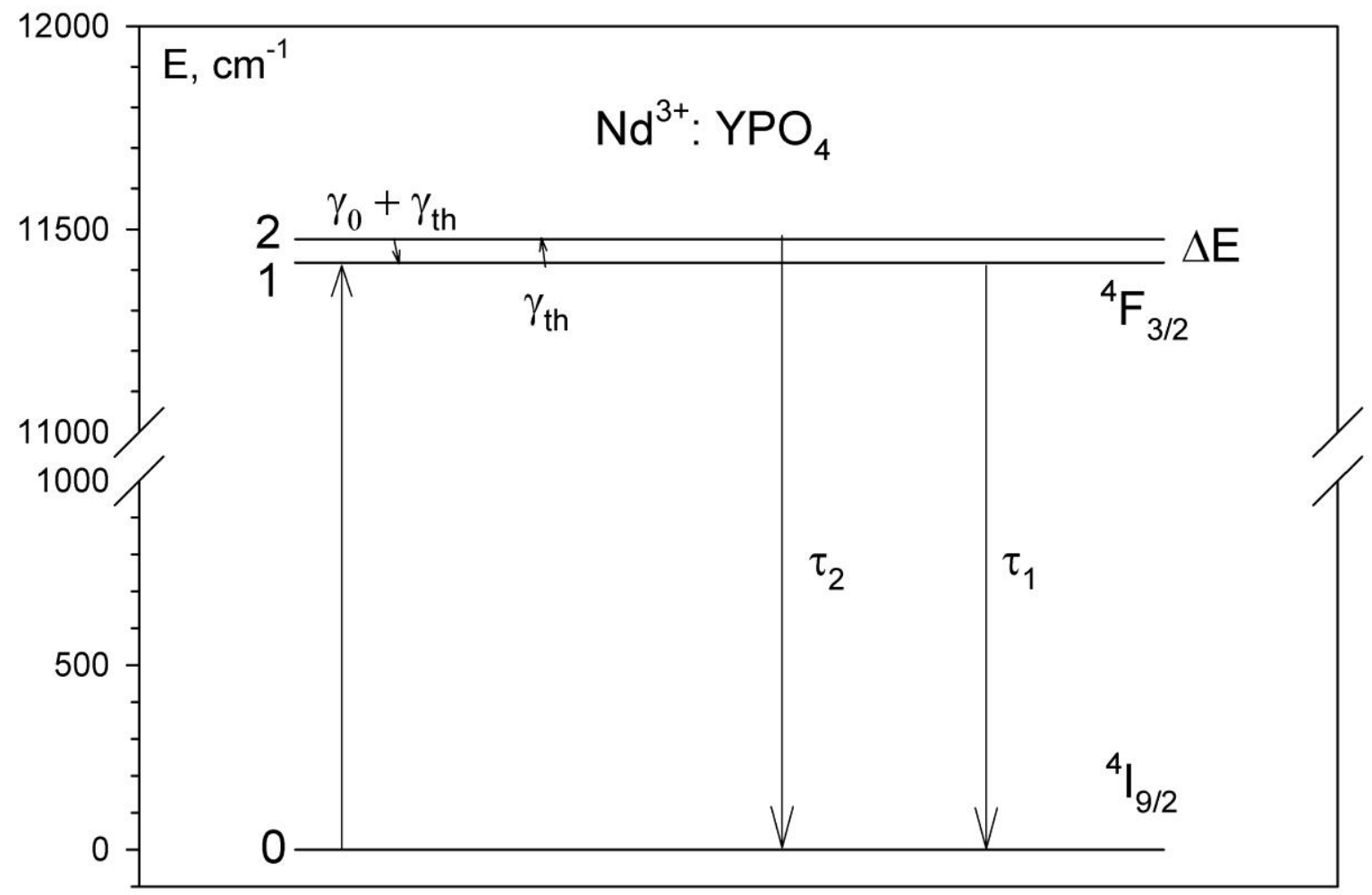

Fig. 1 Three-level energy diagram in the $\mathrm{YPO}_{4}$ crystal doped by $\mathrm{Nd}^{3+}$, where $\Delta \mathrm{E}=52 \mathrm{~cm}^{-1}$.

In this work the focus is on the obstacles that arise when using $\mathrm{Nd}^{3+}$ doped crystalline nanoparticles for kinetic and spectroscopic temperature sensor in the near IR spectral range. Therefore, first fluorescence from the well-studied ${ }^{4} \mathrm{~F}_{3 / 2}$ manifold of the Nd: YAG crystal was tested. The manifold is split into two crystal field levels 1 and 2 . The ${ }^{4} \mathrm{I}_{15 / 2},{ }^{4} \mathrm{I}_{13 / 2},{ }^{4} \mathrm{I}_{11 / 2}$ manifolds and ground ${ }^{4} \mathrm{I}_{9 / 2}$ manifold together can be considered as level 0 , because of fast nanosecond multiphonon relaxation from the higher lying ${ }^{4} \mathrm{I}_{\mathrm{J}}$ levels to the ${ }^{4} \mathrm{I}_{9 / 2}$ ground level after optical transitions from the ${ }^{4} \mathrm{~F}_{3 / 2}$ level. The ${ }^{4} \mathrm{I}_{\mathrm{J}}$ manifolds can be considered as one level 0 , because the estimated lifetime of the ${ }^{4} F_{3 / 2}$ manifold is hundreds of microseconds [8]. 
Usually in various applications the Nd: YAG crystal is considered as a single-site crystal. However, there exist several optical sites [8], which may lead to some problems while using it for kinetic and spectroscopic temperature sensor in physiological range. This obstacle is rather general, because other crystals, which are broadly used in the literature, e.g. $\mathrm{Nd}^{3+}$ : $\mathrm{LaF}_{3}$, have even more types of optical centers [9]. Besides, the concentration of each optical center type strongly depends on the overall dopant concentration. In this regard, the calibration of the thermometer must be provided for each concentration of dopant, which is difficult to control with required accuracy. In this work the influence of multi-site structure of the crystals on the temperature measurements is shown and the requirements for good temperature sensor based on the $\mathrm{Nd}^{3+}$ doped crystalline particles are formulated. 


\section{Theoretical background}

\subsection{Kinetic method}

The kinetic method can be applied if the temperature dependence of the decay of spontaneous luminescence kinetics has an analytical solution.-This refers to the case of three levels system describing the relaxation of the ${ }^{4} \mathrm{~F}_{3 / 2}$ level of the $\mathrm{Nd}^{3+}$ ion. It obeys a simple exponential law with the decay rate $1 / \tau_{\text {meas. }}=W^{\mathrm{eq}}(T)$. The temperature dependence of the decay rate corresponds to the contribution of each level spontaneous decay rate according to their equilibrium population as per following expressions [10-11]

$$
\begin{gathered}
n_{1}^{e q}(T)=\frac{1}{1+\exp \left(-\frac{\Delta E}{k T}\right)}, \quad n_{2}^{e q}(T)=\frac{\exp \left(-\frac{\Delta E}{k T}\right)}{1+\exp \left(-\frac{\Delta E}{k T}\right)} \\
n_{1}(t)=n_{1}^{e q}(T) \exp \left[-W^{e q}(T) t\right] \\
n_{2}(t)=n_{2}^{e q}(T) \exp \left[-W^{e q}(T) t\right]
\end{gathered}
$$

with equal decay rates $W^{\mathrm{eq}}(T)$,

$$
W^{e q}(T)=\frac{n_{1}^{e q}(T)}{\tau_{1}}+\frac{n_{2}^{e q}(T)}{\tau_{2}}
$$

in which the spontaneous emission rate of each level contributes according to their equilibrium population $n_{2}^{e q}(T) / n_{1}^{e q}(T)=\exp (-\Delta E / k T)$.

At the low temperatures only lower level 1 is filled so the decay rate is determined by the rate of the spontaneous decay $A_{10}=1 / \tau_{1}$ of the level 1

$$
W^{e q}(T) \approx \frac{n_{1}^{e q}(T)}{\tau_{1}} \approx \frac{1}{\tau_{1}}
$$

The $\tau_{1}$ may be thus easily measured at the temperatures in the range $7-10 \mathrm{~K}$. If $\tau_{1}$ and $\tau_{2}$ are temperature independent, the measured temperature dependence of luminescence decay time is described by the expression (4) with fixed value of $\tau_{2}$. 
The relative sensitivity of the kinetic method for temperature measurement if $\tau_{1}$ and $\tau_{2}$ are temperature independent constants is described by the following:

$$
\frac{1}{W^{e q}(T)} \frac{d W^{e q}(T)}{d T}=\frac{1}{T}\left(\frac{1}{\tau_{2}}-\frac{1}{\tau_{1}}\right)\left[\frac{\frac{\Delta E}{k T} \exp \left(-\frac{\Delta E}{k T}\right)}{\left(1+\exp \left(-\frac{\Delta E}{k T}\right)\right)^{2}}\right] \frac{1}{W^{e q}(T)}=\frac{1}{T}\left(\frac{1}{\tau_{2}}-\frac{1}{\tau_{1}}\right)\left(\frac{\Delta E}{k T}\right) \frac{n_{1}^{e q}(T) n_{2}^{e q}(T)}{W^{e q}(T)}
$$

At the limit of low temperatures the expression (6) approaches zero, since the equilibrium population of the upper Stark level $n_{2}(T)$ exponentially approaches zero. In this case, as follows from (5), the $W^{\mathrm{eq}}(T)$ is temperature independent. The sensitivity, thus, equals to zero. At sufficiently high temperatures the serial expansion of the (6) is given by following formula

$$
\frac{1}{W^{e q}(T)} \frac{d W^{e q}(T)}{d T} \approx \frac{1}{2 T}\left(\frac{\Delta E}{k T}\right) \frac{\left(\frac{1}{\tau_{2}}-\frac{1}{\tau_{1}}\right)}{\left(\frac{1}{\tau_{2}}+\frac{1}{\tau_{1}}\right)} \quad k T>>\Delta E
$$

To obtain Eq. (7) the high-temperature limit for $W^{\mathrm{eq}}(T)$ was used.

$$
W^{e q}(T) \approx \frac{1}{2}\left(\frac{1}{\tau_{1}}+\frac{1}{\tau_{2}}\right), \quad k T>>\Delta E
$$

It is worthy to note that the sensitivity of the kinetic method increases with the increase of the $\Delta E$ and of the difference between $\tau_{1}$ and $\tau_{2}$.

\subsection{FIR method}

Another method of temperature control is based on the temperature dependence of the fluorescence intensity ratio (FIR) [7, 12] measured for two spectral lines from levels 1 and 2 to level 0 . The ratio does not depend on the number of Stark levels of the excited manifold (any two levels may be selected) and obeys the following equation

$$
\frac{I_{2}(t)}{I_{1}(t)}=\frac{\beta_{20} A_{2} n_{2}^{e q}(T) h v_{2}}{\beta_{10} A_{1} n_{1}^{e q}(T) h v_{1}} \square \frac{A_{2}}{A_{1}} \exp \left(-\frac{\Delta E}{k T}\right)
$$

where $\beta_{\mathrm{i} 0}$ is the branching ratio factor of spontaneous emission rate at selected transition; $A_{2}=$ $1 / \tau_{2}$ and $A_{1}=1 / \tau_{1}$ are total rate of spontaneous decay from every selected level to all lower 
levels; $h v_{2}$ and $h v_{1}$ are transition energies, and $\Delta E$ is the difference in energy between the selected Stark levels of the same or the neighboring manifolds. Taking into account that the $h v_{1}$ and $h v_{2}$ values are approximately equal and assuming that branching factors $\beta_{20}$ and $\beta_{10}$ of the spontaneous decay to the ground level 0 are approximately equal too, one comes to the last part of (10).

The relative sensitivity of the spectral method is obtained by differentiating of equation (10)

$$
\frac{d\left(\frac{I_{2}(t)}{I_{1}(t)}\right)}{d T\left(\frac{I_{2}(t)}{I_{1}(t)}\right)} \approx \frac{\frac{A_{2}}{A_{1}} \frac{1}{T} \frac{\Delta E}{k T} \exp \left(-\frac{\Delta E}{k T}\right)}{\frac{A_{2}}{A_{1}} \exp \left(-\frac{\Delta E}{k T}\right)}=\frac{1}{T} \frac{\Delta E}{k T}
$$

As a result, the sensitivity increases with the increase of $\Delta E$. The spectral method is thus preferable at low temperatures, when the sensitivity is maximal, while the sensitivity of the kinetic method is close to zero. At the temperatures required for medical applications (physiological range) the sensitivity ratio for two methods is temperature independent. Indeed, dividing (7) by (11), one comes to

$$
\frac{S_{k i n}}{S_{\text {spec }}}=\frac{1}{2} \frac{\left(\frac{1}{\tau_{2}}-\frac{1}{\tau_{1}}\right)}{\left(\frac{1}{\tau_{2}}+\frac{1}{\tau_{1}}\right)}, \quad k T>\Delta E
$$

It is evident that when lifetimes differ significantly, the ratio is close to $1 / 2$. This result applies to the situation when $\tau_{1}$ and $\tau_{2}$ are temperature independent. Thus, in the physiological temperature range the sensitivity of the spectral method slightly exceeds the one for the kinetic method. 


\section{Material and methods}

In this study to reveal the influence of matrix and morphology on the fluorescnent temperature measurement three differently prepared samples were used: Nd-doped YAG bulk crystal, the microcrystalline Nd: YAG and the nanocrystalline Nd: $\mathrm{YPO}_{4}$ powders.

As a model object to evaluate the capabilities of the kinetic method for chosen energy levels scheme the $0.1 \% \mathrm{Nd}^{3+}$ : YAG single-crystal synthesized by Chokhralskii method in A.M. Prokhorov General Physics Institute free from fluorescence quenching caused by the vibrations of the $\mathrm{OH}^{-}$groups [13] was employed. Besides, according to literature data [14], the Stark splitting of the ${ }^{4} \mathrm{~F}_{3 / 2}$ level of the $\mathrm{Nd}^{3+}$ in the $\mathrm{Nd}^{3+}$ : YAG single-crystal is larger $(\Delta E=$ $85 \mathrm{~cm}^{-1}$ ) than for widely used $\mathrm{Nd}^{3+}: \mathrm{LaF}_{3},\left(\Delta E=42 \mathrm{~cm}^{-1}\right)$ (Fig. 3).

For the powders as starting compounds $\mathrm{Al}\left(\mathrm{NO}_{3}\right)_{3} \cdot 9 \mathrm{H}_{2} \mathrm{O}$ (Aldrich, $99.99 \%$ purity), $\mathrm{Y}\left(\mathrm{NO}_{3}\right)_{3} \cdot 4 \mathrm{H}_{2} \mathrm{O}$ (Aldrich, $99.999 \%$ purity), $\mathrm{Nd}\left(\mathrm{NO}_{3}\right)_{3} \cdot 5 \mathrm{H}_{2} \mathrm{O}$ (Aldrich, $99.999 \%$ purity), $\mathrm{K}_{2} \mathrm{HPO}_{4} \cdot 3 \mathrm{H}_{2} \mathrm{O}$ (Aldrich, $99.9 \%$ purity), $30 \% \mathrm{NH}_{4} \mathrm{OH}$ solution (Merck, analytical grade) were used.

The X-ray diffraction analysis of the NPs was performed using the «Rigaku D/MAX 2500» diffractometer ( $\mathrm{CuK} \alpha$-radiation) and the JCPDS database was used to identify the diffraction peaks.

\section{1. $0.1 \% \mathrm{Nd}^{3+}: \mathrm{YPO}_{4}$}

For the synthesis of the xenotime-type $0.1 \mathrm{~mol} \% \mathrm{Nd}^{3+}: \mathrm{YPO}_{4}$ nanoparticles the solution of $\mathrm{Y}\left(\mathrm{NO}_{3}\right)_{3} \cdot 4 \mathrm{H}_{2} \mathrm{O}(4.995 \mathrm{mmols})$ and $\mathrm{Nd}\left(\mathrm{NO}_{3}\right)_{3} \cdot 5 \mathrm{H}_{2} \mathrm{O}(0.005 \mathrm{mmol})$ in $10 \mathrm{ml}$ of deionized water was prepared as well as solution of 5 mmols of $\mathrm{K}_{2} \mathrm{HPO}_{4} \cdot 3 \mathrm{H}_{2} \mathrm{O}$ in $30 \mathrm{ml}$ of deionized water. After that the solution of nitrates was added dropwise to the solution of phosphate under vigorous stirring and left for 15 min keeping the stirring on. The freshly precipitated gel was diluted in mother solution with $10 \mathrm{ml}$ of deionized water, transfered into $100 \mathrm{ml}$ Teflon autoclave and exposed to microwave-hydrothermal (MW-HT) treatment at $200^{\circ} \mathrm{C}$ for 2 hours using Berghof Speedwave-3M+ laboratory device (2.45 GHz, $1 \mathrm{~kW}$ maximum output power). After treatment the sample was centrifuged, washed several times with deionized water and air-dried at $200^{\circ} \mathrm{C}$ for 2 hours. To obtain orthophosphate nanoparticles more or less free of water and surface $-\mathrm{OH}$ groups the $0.1 \mathrm{~mol} \% \mathrm{Nd}^{3+}: \mathrm{YPO}_{4}$ sample was annealed at high temperature at $900^{\circ} \mathrm{C}$ for 5 hours. 
According to the XRD data $\mathrm{YPO}_{4}$ : $\mathrm{Nd}^{3+}$ particles are well crystallized and do not contain any impurities. TEM data shows that the mean size of the nanoparticles is $50 \pm 15 \mathrm{~nm}$, but the high temperature treatment at $900{ }^{\circ} \mathrm{C}$ leads to strong aggregation and growth of the particles, which cannot be dispersed afterwards. $[13,15]$

\section{2. $1 \% \mathrm{Nd}^{3+}$ :YAG}

Neodymium-doped yttrium aluminum garnet $\left(1 \% \mathrm{Nd}^{3+}: \mathrm{Y}_{3} \mathrm{Al}_{5} \mathrm{O}_{12}\right)$ micropowder was prepared by standard co-precipitation technique. For this purpose stoichiometric amounts of yttrium, aluminum and neodymium nitrates were dissolved in deionized water. Solution was added dropwise to the $\mathrm{x} 5$ excess of $30 \%$ ammonia water solution. Obtained precipitate was washed several times with deionized water and dried at $100^{\circ} \mathrm{C}$ for 5 hours. After that dry powder was grinded, pressed into a pellet and calcined at $500^{\circ} \mathrm{C}$ for 5 hours, ground and pressed into pellet again and calcined at $1000^{\circ} \mathrm{C}$ for 10 hours.

An XRD analysis of obtained sample of $1 \% \mathrm{Nd}^{3+}: \mathrm{Y}_{3} \mathrm{Al}_{5} 0_{12}$ (Fig. 2) showed that it consists of pure $\mathrm{Y}_{3} \mathrm{Al}_{5} 0_{12}$ (PDF2 ref. card \# 33-40) with cell parameter $a=12.0381(8) \AA$ and coherent scattering domain size $\sim 80 \mathrm{~nm}$. Powder is characterized by high degree of crystallinity and highly aggregated microparticles due to prolonged calcination at high temperature.

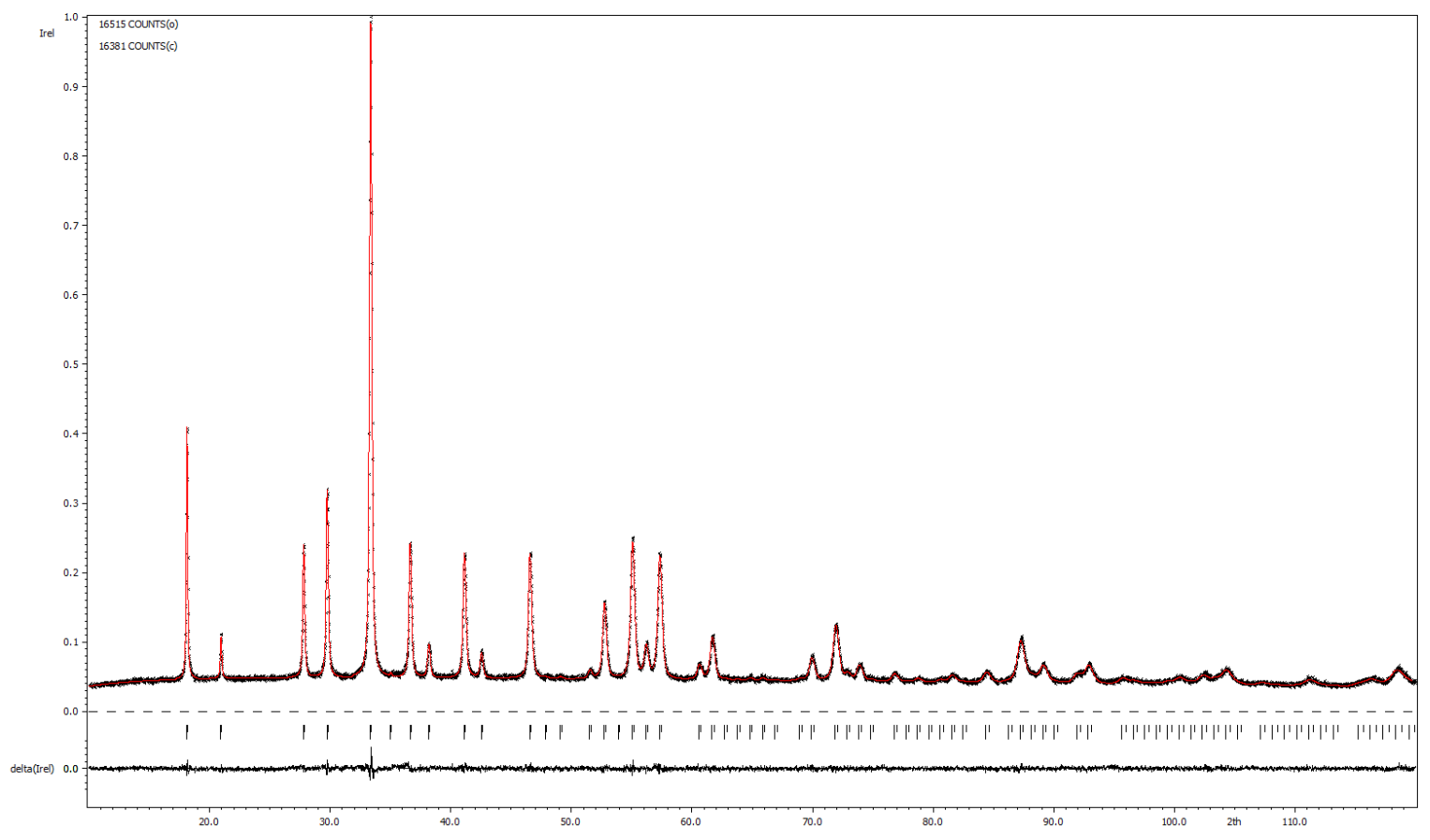

Fig. 2 XRD pattern of the synthesized $1 \% \mathrm{Nd}^{3+}: \mathrm{Y}_{3} \mathrm{Al}_{5} \mathrm{O}_{12}$ sample. 


\subsection{Experimental setup}

The fluorescence kinetics was measured in the near-infrared spectral range using pulsed laser excitation from an optical parametric oscillator (OPO) Ekspla NT342/1/UVE $\left(t_{\mathrm{p}}=15 \mathrm{~ns}, f=\right.$ $20 \mathrm{~Hz}$ ). The fluorescence is dispersed by Andor SR303i spectrometer and detected by a photomultiplier Pheu-79 in photon counting mode with multi-channel analyzer (Fast Comtec P7882) with $100 \mathrm{~ns}$ time resolution. The BLP-785R and BLP01-808R-25 edge-filters (Semrock) depending on excitation wavelength were attached to the front slit of the monochromator to prevent the entry of scattered light originating from the laser excitation. Site-selective fluorescence spectra were detected by gated Andor Technology iCCD camera iStar DH320T-18H-13.

The measurements of the temperature dependence for both fluorescence spectra and kinetics in Nd:YAG crystal were performed in the closed cycle helium cryostat Janis with cold finger (Model CCS-300S/204N sub-compact optical cryostat system), allowing to cool the single crystal down to 7K. For nanoparticles UTREKS-type helium-bath cryostat was used, since the thermal contact of the cuvette containing nanoparticles powder with the cold finger proved to be insufficient to cool the nanoparticles to the target temperature due to their heating after laser excitation as a result of multiphonon relaxation. The presence of the fluorescence line originated from the second Stark level of the ${ }^{4} \mathrm{~F}_{3 / 2}$ manifold is the criterion of the heating. Linkam THMS350V heating/cooling stage was employed to measure the temperature dependence of the fluorescence kinetics and spectra at $\mathrm{T}>150 \mathrm{~K}$. 


\section{Results and the analysis}

For testing both the methods the $0.1 \% \mathrm{Nd}^{3+}$ : YAG bulk single-crystal, $1 \% \mathrm{Nd}^{3+}$ : YAG microparticles, and $0.1 \% \mathrm{Nd}^{3+}: \mathrm{YPO}_{4}$ nanoparticles were used. To increase the sensitivity of both temperature measurement methods YAG oxide matrix was first emplyed for $\mathrm{Nd}^{3+}$ doping, which have srtonger crystal-field splitting of the $\mathrm{Nd}^{3+}$ manifolds (wider $\Delta E$ ) than in fluorides and phosphates [16]. Contrariwise the chosen crystalline matrixes have higher maximal phonon frequencies than fluorides. As a result in the temperature range of interest the higher lying ${ }^{4} \mathrm{~F}_{5 / 2}$ manifold can be populated possibly causing some problems in the analysis of fluorescence lifetime temperature dependence limited by three level approximation. On the other hand allows populating the crystal field levels of the ${ }^{4} \mathrm{~F}_{5 / 2}$ manifold in physiological temperature range, thus makes possible to increase the sensitivity of FIR method employing electronic levels with energy difference $\Delta E>1000 \mathrm{~cm}^{-1}$.

\subsection{Kinetic method}

The fluorescence in the samples in study was excited with optical parametric oscillator (OPO) at wavelengths within first biological transparency window at the ${ }^{4} \mathrm{I}_{9 / 2} \rightarrow{ }^{4} \mathrm{~F}_{5 / 2}+{ }^{2} \mathrm{H}_{9 / 2}$ transition of the $\mathrm{Nd}^{3+}$ ion. Sometimes the excitation at the ${ }^{4} \mathrm{I}_{9 / 2} \rightarrow{ }^{4} \mathrm{G}_{5 / 2}+{ }^{2} \mathrm{G}_{7 / 2}$ transition was used for site selection. In both cases the ${ }^{4} \mathrm{~F}_{3 / 2}$ level is quickly populated after picosecond or nanosecond multiphonon relaxation. Then the thermal equilibrium between two Stark levels of the ${ }^{4} \mathrm{~F}_{3 / 2}$ level is established within picoseconds. The condition of the three-level system is however fulfilled well only at the temperatures lower than the room temperature. At higher temperatures the population of the upper ${ }^{4} \mathrm{~F}_{5 / 2}+{ }^{2} \mathrm{H}_{9 / 2}$ manifold starts and this may lead to misinterpretation of the measured temperature dependence using formulae (1) - (4). As will be shown below, the population of the ${ }^{4} \mathrm{~F}_{5 / 2}+{ }^{2} \mathrm{H}_{9 / 2}$ level of $\mathrm{Nd}^{3+}$ ion at room temperatures gives hope for the implementation of the spectral method for temperature measurement. 


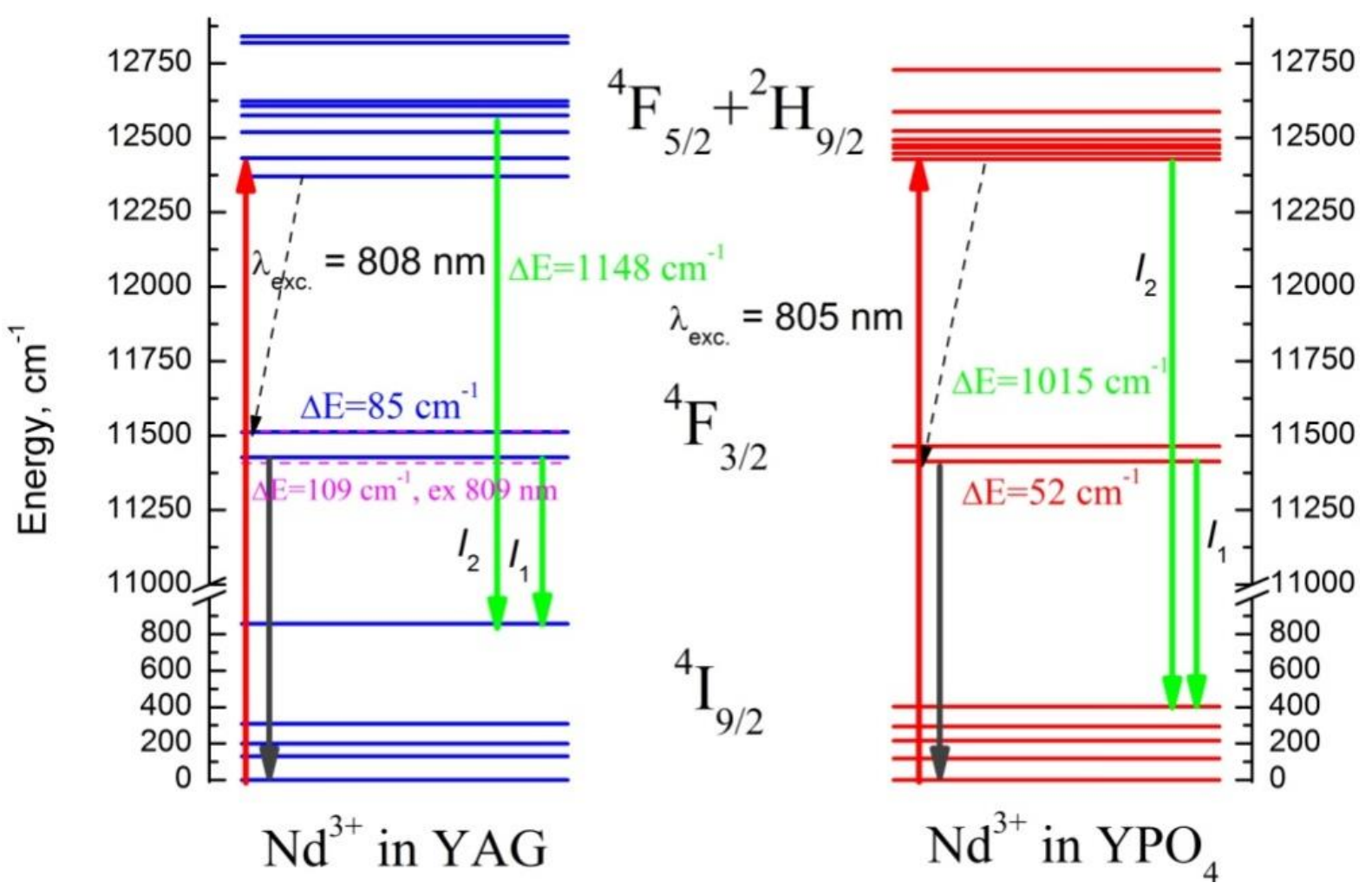

Fig. 3 Energy levels diagram and operating schemes (red and black arrows for the kinetic method and red and green arrows for FIR) for temperature measurement by fluorescence kinetic and spectral methods in $\mathrm{Nd}^{3+}$ : YAG and $\mathrm{Nd}^{3+}$ : $\mathrm{YPO}_{4}$ crystal matrix. The value of Stark splitting of the ${ }^{4} \mathrm{~F}_{3 / 2}$ manifold $(\Delta \mathrm{E})$ for the first optical center in Nd:YAG is in blue color and for the third one in magenta.

The half-width at half-height of the fluorescence spectral line at the ${ }^{4} \mathrm{~F}_{3 / 2}(1) \rightarrow{ }^{4} \mathrm{I}_{9 / 2}$ (1) transition of the $\mathrm{Nd}^{3+}$ ion in the $0.1 \% \mathrm{Nd}^{3+}$ YAG crystal at $10 \mathrm{~K}$ excited at $808 \mathrm{~nm}$ laser wavelength evaluated at the low-frequency part of the line gives $\delta=3.5 \mathrm{~cm}^{-1}$ (Fig. 4, blue curve). It corresponds to a limit of the resolution in this spectral range of the available Semrock monochromator with 1200 grooves/mm grating. The narrow line corresponds to homogenous broadening and relates to one type of optical centers. At the high-frequency wing another weaker spectral line is resolved with maximum shifted by $5.2 \mathrm{~cm}^{-1}$ from the first line. It indicates the presence of the optical centers of a second type. Spectral line width evaluation at the ${ }^{4} \mathrm{~F}_{3 / 2}(1) \rightarrow{ }^{4} \mathrm{I}_{9 / 2}(1)$ transition of the $\mathrm{Nd}^{3+}$ ion in the powder of $1 \% \mathrm{Nd}$ : YAG microparticles results in $\Delta=13.2 \mathrm{~cm}^{-1}$ (Fig. 4, red curve). It is found to be four times wider than homogenously broadened line in a single crystal and points to the inhomogeneous broadening. The broadened spectral line of the optical centers of the second type is also 
presented. As compared to single crystal the shift of the spectral lines maxima to longwavelength spectral range is observed in the powder. Both facts may be related to the presence of sufficient amount of optical centers located close to the surface and exposed to different crystal field as compared to single crystal.

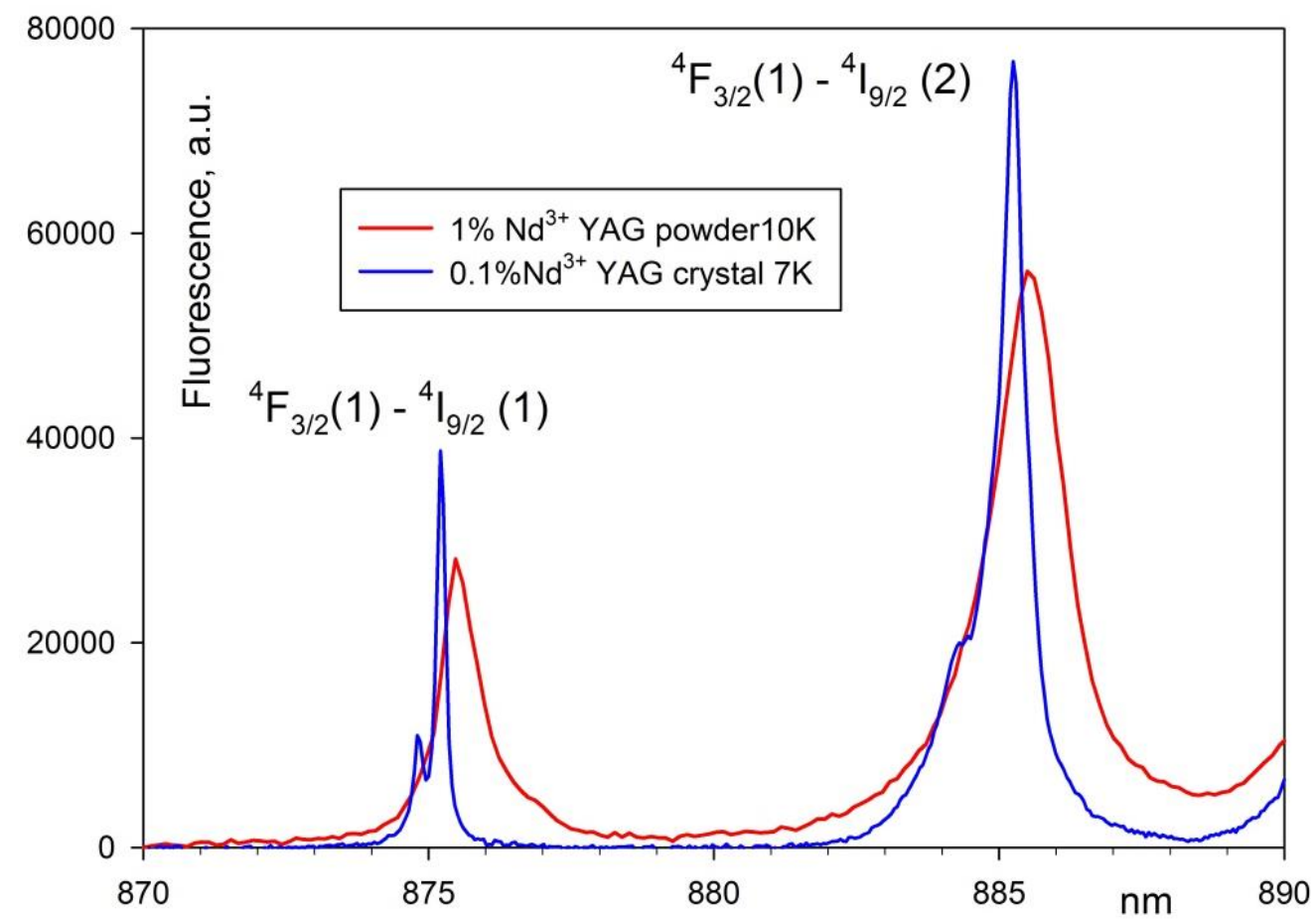

Fig. 4 Fluorescence spectra at the ${ }^{4} \mathrm{~F}_{3 / 2}(1) \rightarrow{ }^{4} \mathrm{I}_{9 / 2}(1)$ and ${ }^{4} \mathrm{~F}_{3 / 2}(1) \rightarrow{ }^{4} \mathrm{I}_{9 / 2}$ (2) transitions of the $\mathrm{Nd}^{3+}$ ion in the $0.1 \% \mathrm{Nd}^{3+}$ YAG crystal at $7 \mathrm{~K}$ (blue curve) and $1 \% \mathrm{Nd}^{3+}$ YAG microparticles at $10 \mathrm{~K}$ (red curve) after laser excitation at $808 \mathrm{~nm}$. 


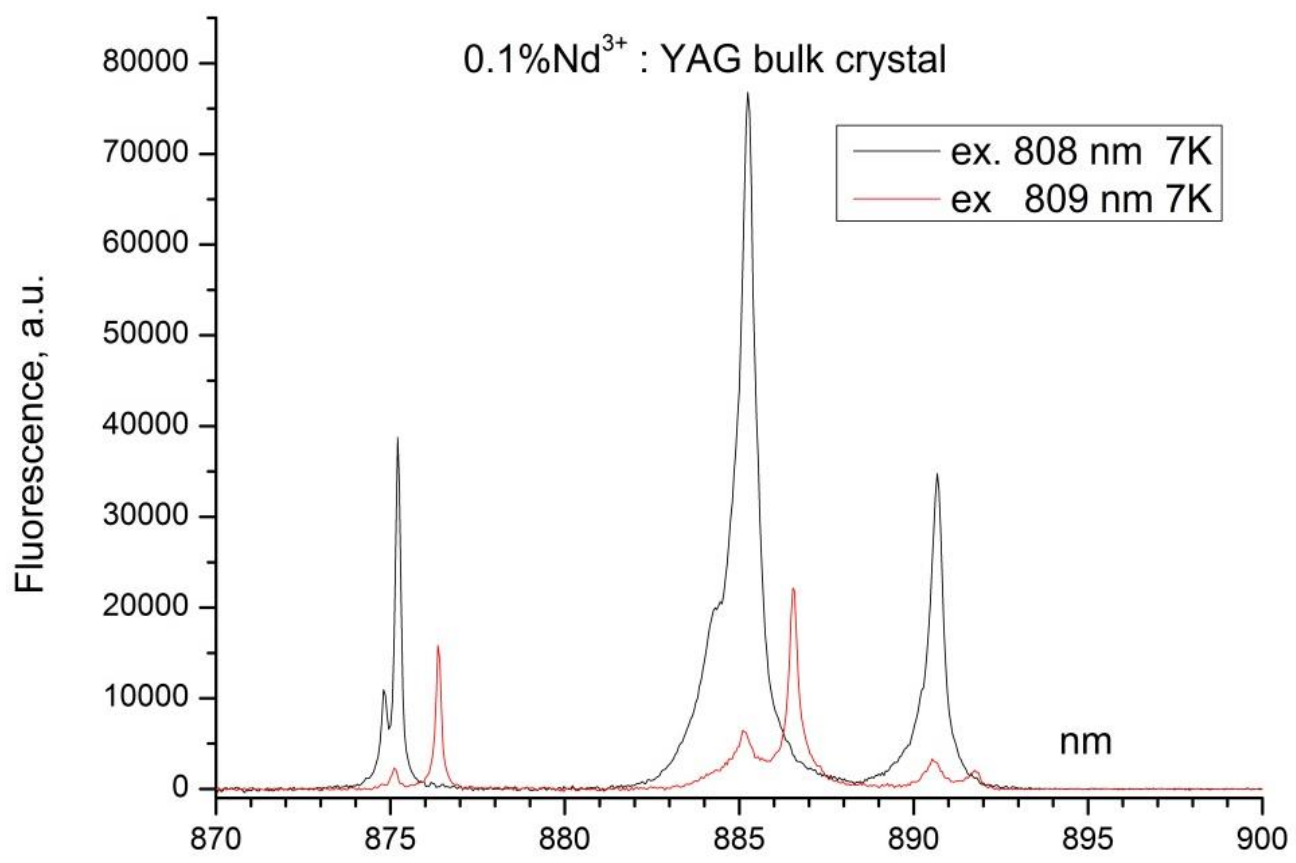

Fig. 5 Fluorescence spectra at the ${ }^{4} \mathrm{~F}_{3 / 2}(1) \rightarrow{ }^{4} \mathrm{I}_{9 / 2}(1,2,3)$ transitions (from left to right respectively) of the $\mathrm{Nd}^{3+}$ ion in the $0.1 \% \mathrm{Nd}^{3+}$ YAG single crystal at $7 \mathrm{~K}$ after laser excitation at $808 \mathrm{~nm}$ (black curve) and $809 \mathrm{~nm}$ (red curve).

When the excitation wavelength is changed from 808 to $809 \mathrm{~nm}$, one more type of optical centers appears. The spectral lines of the third type of optical centers are shifted by $15.1 \mathrm{~cm}^{-1}$ to the long wavelength spectral range comparing to the first one (Fig. 5). At the same time the fluorescence spectral lines of the second type of optical centers are disappeared. The siteselective measurements of the fluorescence kinetics was done for the first and the third type of optical centers only, because of their stronger fluorescence. It is worthy to note that, for example, in [16] only the first type of optical centers is detected and considered.

The temperature increase of the $0.1 \% \mathrm{Nd}^{3+}$ : YAG crystal gives rise to the fluorescence spectral lines at the transitions originated from the second Stark level of the ${ }^{4} F_{3 / 2}$ manifold (Fig. 6). With this, the values of the splitting $\Delta E$ for the first and the third types of optical centers may be determined as $\Delta E=85$ and $109 \mathrm{~cm}^{-1}$, respectively. Thus the sensitivity of the kinetic method for temperature measurement may be higher if the third type of optical centers can be employed. 


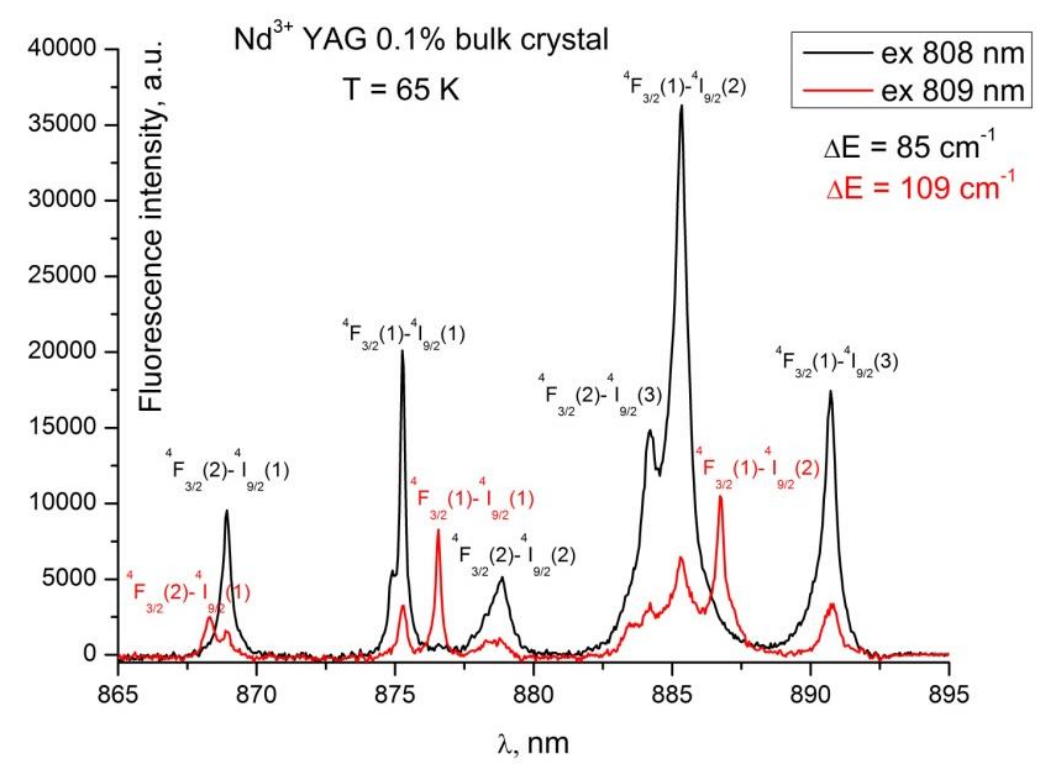

Fig. 6 Fluorescence spectra at the ${ }^{4} \mathrm{~F}_{3 / 2}(2,1) \rightarrow{ }^{4} \mathrm{I}_{9 / 2}(1,2,3)$ transitions (from left to right respectively) of the $\mathrm{Nd}^{3+}$ ion in the $0.1 \% \mathrm{Nd}^{3+} \mathrm{YAG}$ single crystal at $65 \mathrm{~K}$ after laser excitation at $808 \mathrm{~nm}$ (black curve) and $809 \mathrm{~nm}$ (red curve).

The temperature dependence of the fluorescence kinetics of the ${ }^{4} \mathrm{~F}_{3 / 2}$ manifold in the $\mathrm{Nd}^{3+}$ ion in the $0.1 \% \mathrm{Nd}^{3+}$ YAG crystal was measured for the first and the third type of optical centers (Fig. 7).

a)

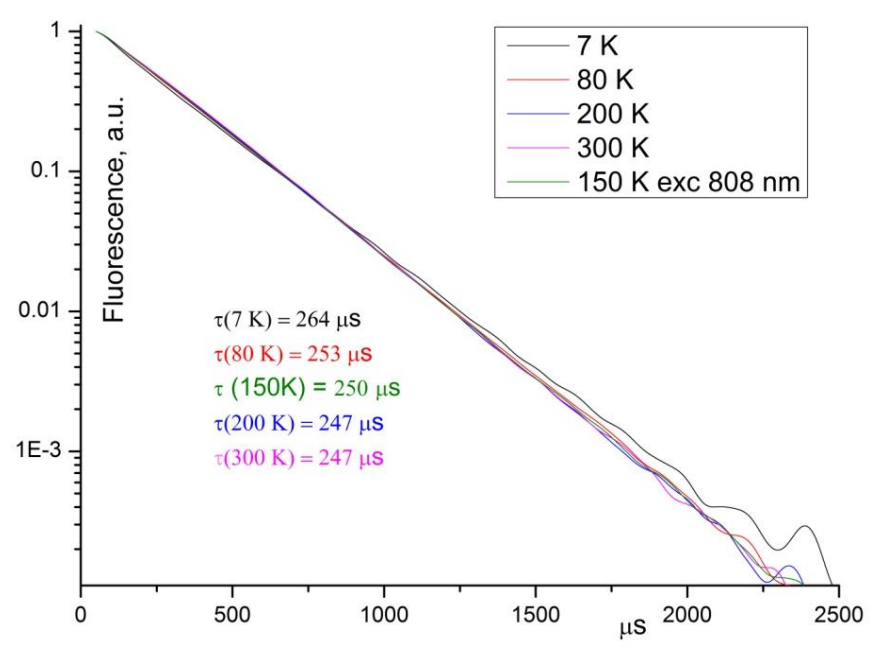

b)

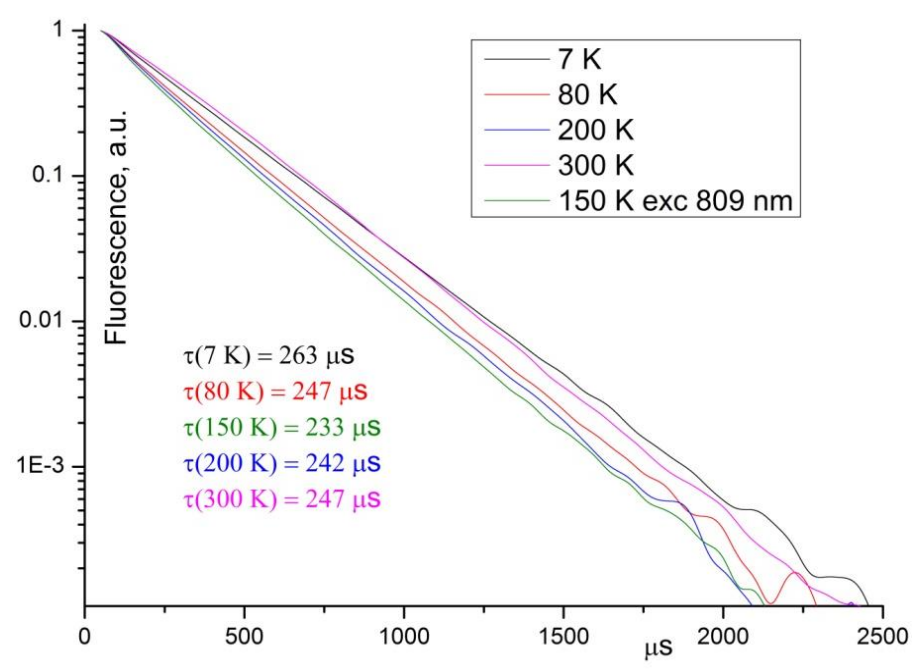

Fig. 7 Fluorescence kinetics at several temperatures for the first (excitation wavelength $808 \mathrm{~nm}$ ) (a) and the third $-809 \mathrm{~nm}$ (b) types of optical centers in the $0.1 \% \mathrm{Nd}^{3+}$ : YAG crystal. 


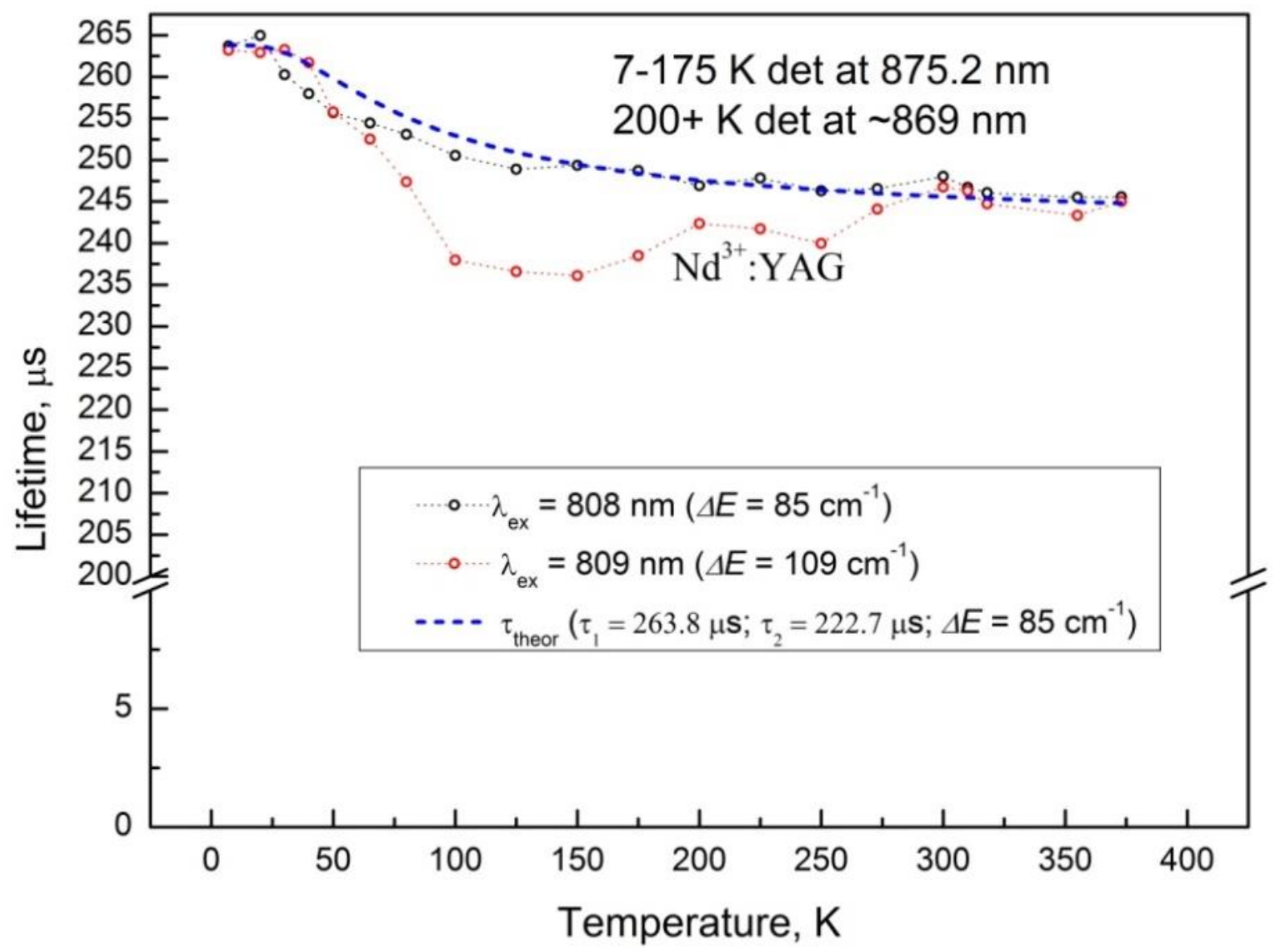

Fig. 8 Measured dependence of the lifetime of the ${ }^{4} \mathrm{~F}_{3 / 2}$ level of the $\mathrm{Nd}^{3+}$ ion in the $0.1 \%$ $\mathrm{Nd}^{3+}$ :YAG single crystal on the temperature for the first (black circles) and third (red circles) types of optical centers. Theoretical dependence (1) - (4) for fixed $\tau_{1}$ and $\tau_{2}$ for the first optical center type (blue dashed line). $\tau_{1}=263.8 \mu \mathrm{s}$ is measured at $\mathrm{T}=7 \mathrm{~K}, \tau_{2}$ - adjustable parameter.

The measured spontaneous emission decay times of the first and third types of optical centers are almost identical at the temperatures lower than 50 and higher than $275 \mathrm{~K}$ (Fig. 8). The measured lifetime at $7 \mathrm{~K}$ is determined by the spontaneous decay lifetime of the lower Stark level of the ${ }^{4} \mathrm{~F}_{3 / 2}$ manifold $\left(\tau\left({ }^{4} \mathrm{~F}_{3 / 2}(1)\right)=263-264 \mu \mathrm{s}\right)$. These values are equal for both types of optical centers at $7 \mathrm{~K}$ and are not substantially different up to $50 \mathrm{~K}$. At $80 \mathrm{~K}$, however, the difference in lifetime for two types of optical centers becomes considerable. While for the first type the lifetime decrease is negligible $\tau_{\text {meas. }}(1)=253 \mu$ s, tor the third type the decrease is $10 \%\left(\tau_{\text {meas. }}(3)=237 \mu \mathrm{s}\right)$. Whereupon the lifetime is stabilized at the minimum value and then grows up to the temperature of $275 \mathrm{~K}$. At higher temperatures the measured lifetime values for both types of optical centers are almost identical which is apparently relates to the absence of fluorescence excitation selectivity. This assumption is confirmed by almost identical form 
factor of the fluorescence spectra measured at $310 \mathrm{~K}\left(37^{\circ} \mathrm{C}\right)$ by laser excitation at 808 and 809 nm wavelengths (Fig. 9). Since at high temperatures the fluorescence kinetic remains exponential for both excitation wavelengths (Fig. 8), one may conclude that at high temperatures the fluorescence kinetics and lifetime are measured for the first type of optical centers due to its higher concentration in comparison with the third one. As a result, the actual temperature dependence of the third type of optical centers lifetime cannot be measured due to the absence of site selection. It should be noted however that in the $40-100 \mathrm{~K}$ range the fluorescence kinetics for this type of optical centers is temperature-sensitive $\left(S_{R}=0.14 \%\right.$ $\mathrm{K}^{-1}$ ) and might be used as temperature sensor unlike the kinetics for the first type of centers.

For the first type of centers the measured lifetime stays almost constant in the whole range of measured temperatures and its temperature dependence obeys well the formulae (1) - (4) at $\Delta E=85 \mathrm{~cm}^{-1}$ with adjustable parameter $\tau_{2}=222.7 \mu \mathrm{s}$. Rather narrow energy gap $\Delta E$ between two Stark levels of the ${ }^{4} \mathrm{~F}_{3 / 2}$ manifold and insignificant divergence of their spontaneous lifetime $\tau_{1}$ and $\tau_{2}$ lead to low sensitivity of such temperature sensor (Eq. (6)). Unfortunately, we have not managed to detect the influence of the higher lying ${ }^{4} \mathrm{~F}_{5 / 2}$ level with $\Delta E>1000$ $\mathrm{cm}^{-1}$ to the measured lifetime, which could increase the sensitivity of the method. As a result one may conclude that using $\mathrm{Nd}^{3+}$ :YAG crystalline nanoparticles for temperature measurements in physiological range by luminescence kinetic method is hardly possible. However, analysis of energy levels and crystal-field splitting of $\mathrm{Nd}^{3+}$ ion in different crystal matrixes revealed that, for example, there is the $\mathrm{Nd}^{3+}: \mathrm{LiNbO}_{3}$ crystal with larger C.F. splitting including the ${ }^{4} \mathrm{~F}_{3 / 2}$ level $\left(\Delta E=159 \mathrm{~cm}^{-1}\right)$ [16] and, therefore, smaller energy gap between the ${ }^{4} \mathrm{~F}_{5 / 2}$ and ${ }^{4} \mathrm{~F}_{3 / 2}$ levels $\left(\Delta E=724 \mathrm{~cm}^{-1}\right)$. It is worthy to stress that the difference of spontaneous emission probability $A\left(\tau_{\mathrm{rad}}\right)$ from different manifolds with different $J$ might be bigger than that from different C.F. levels of the same manifold. This according to Eq. (6) gives chance to increase the sensitivity of the kinetics method of temperature measurement using Boltzman distribution of population between two different manifolds rather than between C.F. levels within one manifold. 


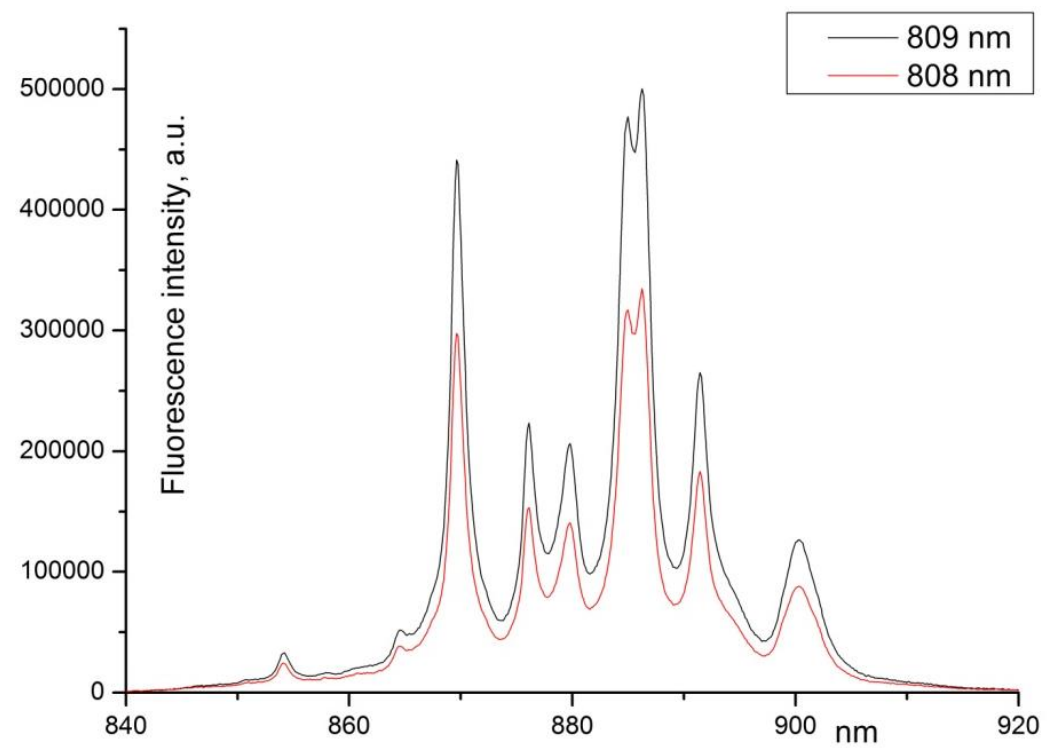

Fig. 9 Fluorescence spectra at the ${ }^{4} \mathrm{~F}_{3 / 2} \rightarrow{ }^{4} \mathrm{I}_{9 / 2}$ transitions of the $\mathrm{Nd}^{3+}$ ion in the $0.1 \% \mathrm{Nd}^{3+}$ YAG single crystal at $310 \mathrm{~K}$ after laser excitation at $808 \mathrm{~nm}$ (red curve) and $809 \mathrm{~nm}$ (black curve).

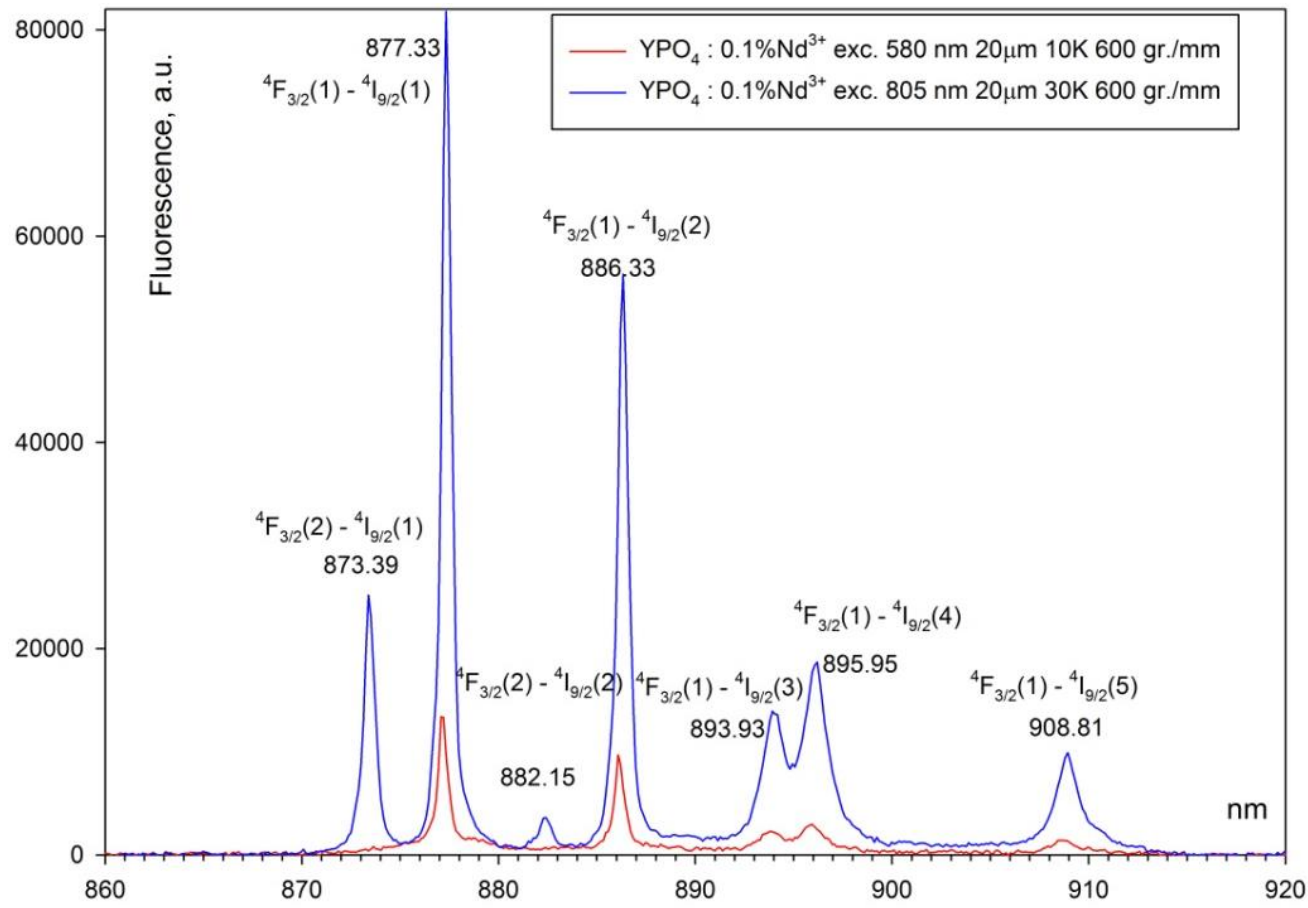

Fig. 10 Fluorescence spectra at the ${ }^{4} \mathrm{~F}_{3 / 2} \rightarrow{ }^{4} \mathrm{I}_{9 / 2}$ transitions of the $\mathrm{Nd}^{3+}$ ion in the $0.1 \% \mathrm{Nd}^{3+}$ : $\mathrm{YPO}_{4}$ nanoparticles after laser excitation at $580 \mathrm{~nm}, 10 \mathrm{~K}$ (red curve) and at $805 \mathrm{~nm}, 30 \mathrm{~K}$ (blue curve).

Unlike the $\mathrm{Nd}^{3+}$ : YAG crystal matrix the $0.1 \% \mathrm{Nd}^{3+}$ : $\mathrm{YPO}_{4}$ nanocrystals have only one type of optical centers. At low temperatures the fluorescence spectrum shows very narrow lines 
with the position and quantity independent of the excitation wavelength (Fig. 10). The width of the spectral line measured at half-height for the ${ }^{4} \mathrm{~F}_{3 / 2}(1) \rightarrow{ }^{4} \mathrm{I}_{9 / 2}(1)$ transition $\left(4 \mathrm{~cm}^{-1}\right)$ does not exceed the resolution of the spectrometer. However, the Stark splitting of the ${ }^{4} \mathrm{~F}_{3 / 2}$ manifold $\Delta E=52 \mathrm{~cm}^{-1}$ is less than for $\mathrm{Nd}^{3+}$ : YAG (Fig. 3). The fluorescence kinetics, except for short initial stage associated with fluorescence quenching caused by vibrations of $-\mathrm{OH}$ groups positioned inside the nanoparticles [13], demonstrates the exponential decay (Fig. 11). At $10 \mathrm{~K}$ the measured lifetime is $\tau_{1}=338 \mu \mathrm{s}$. At $20 \mathrm{~K}$ it grows slightly to $350 \mu \mathrm{s}$, and then decreases quickly by $15 \%$ to $296 \mu$ s at $100 \mathrm{~K}$ (Fig. 12). Thus, in this temperature range the $0.1 \% \mathrm{Nd}^{3+}: \mathrm{YPO}_{4} \mathrm{NPs}$ can be used as a temperature sensor with $\left(S_{\mathrm{R}}=0.2 \%{ }^{\circ} \mathrm{K}^{-1}\right)$. The lifetime is henceforth stabilized and even increases starting from $275 \mathrm{~K}$. This increase however is rather small and does not exceed $5 \%$. On the whole, the temperature dependence of the measured lifetime obeys well formulae (1) - (4) at constant values $\tau_{1}=338$ and $\tau_{2}=$ $256.5 \mu$ s with deviations of experimental values from the theoretical curve within $3 \%$. The lifetime in $0.1 \% \mathrm{Nd}^{3+}: \mathrm{YPO}_{4}$ turns out to be circa $20 \%$ longer than in $0.1 \% \mathrm{Nd}^{3+}$ : YAG crystal. In the physiological range of temperatures the lifetime is almost unchanging which does not allow using the $\mathrm{Nd}^{3+}: \mathrm{YPO}_{4}$ nanoparticles as temperature sensor with kinetic measurement method for medical applications.

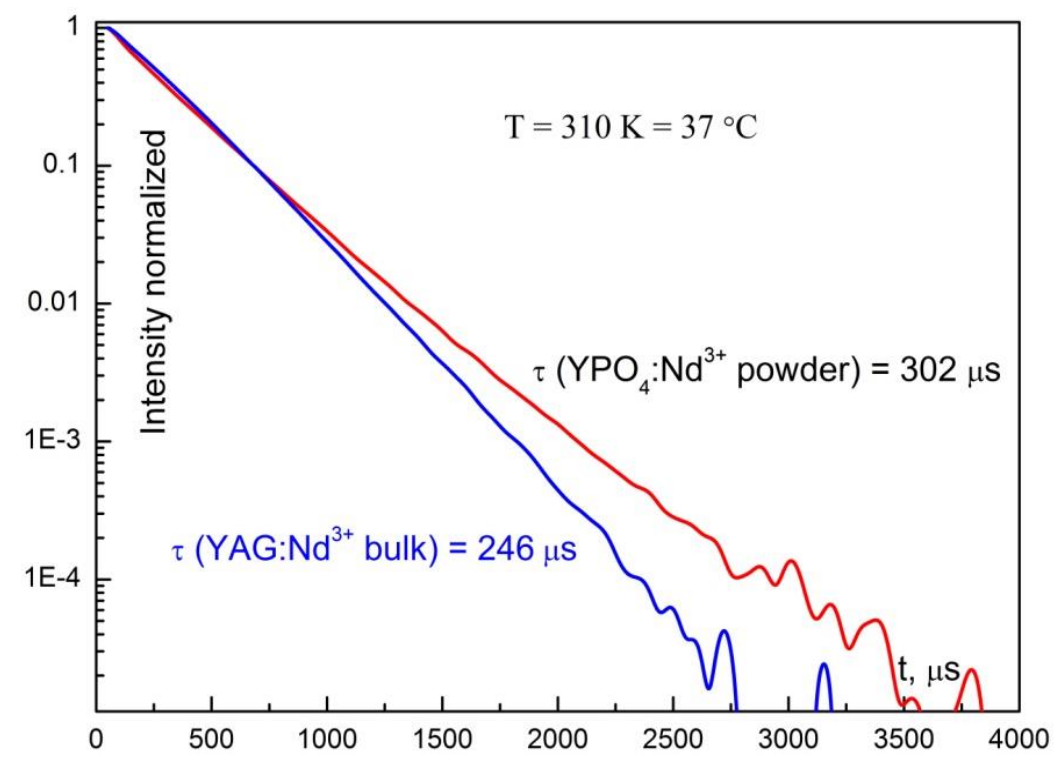

Fig. 11 Fluorescence kinetics of the ${ }^{4} \mathrm{~F}_{3 / 2}$ manifold of the $\mathrm{Nd}^{3+}$ ion in the $0.1 \% \mathrm{Nd}^{3+}: \mathrm{YPO}_{4}$ nanocrystals at $310 \mathrm{~K}$, measured after $580 \mathrm{~nm}$ laser excitation and detected at $873 \mathrm{~nm}$ (red curve) compared to the fluorescence kinetics of the first type optical centers in the $\mathrm{Nd}^{3+}$ : YAG single crystal (blue curve). 


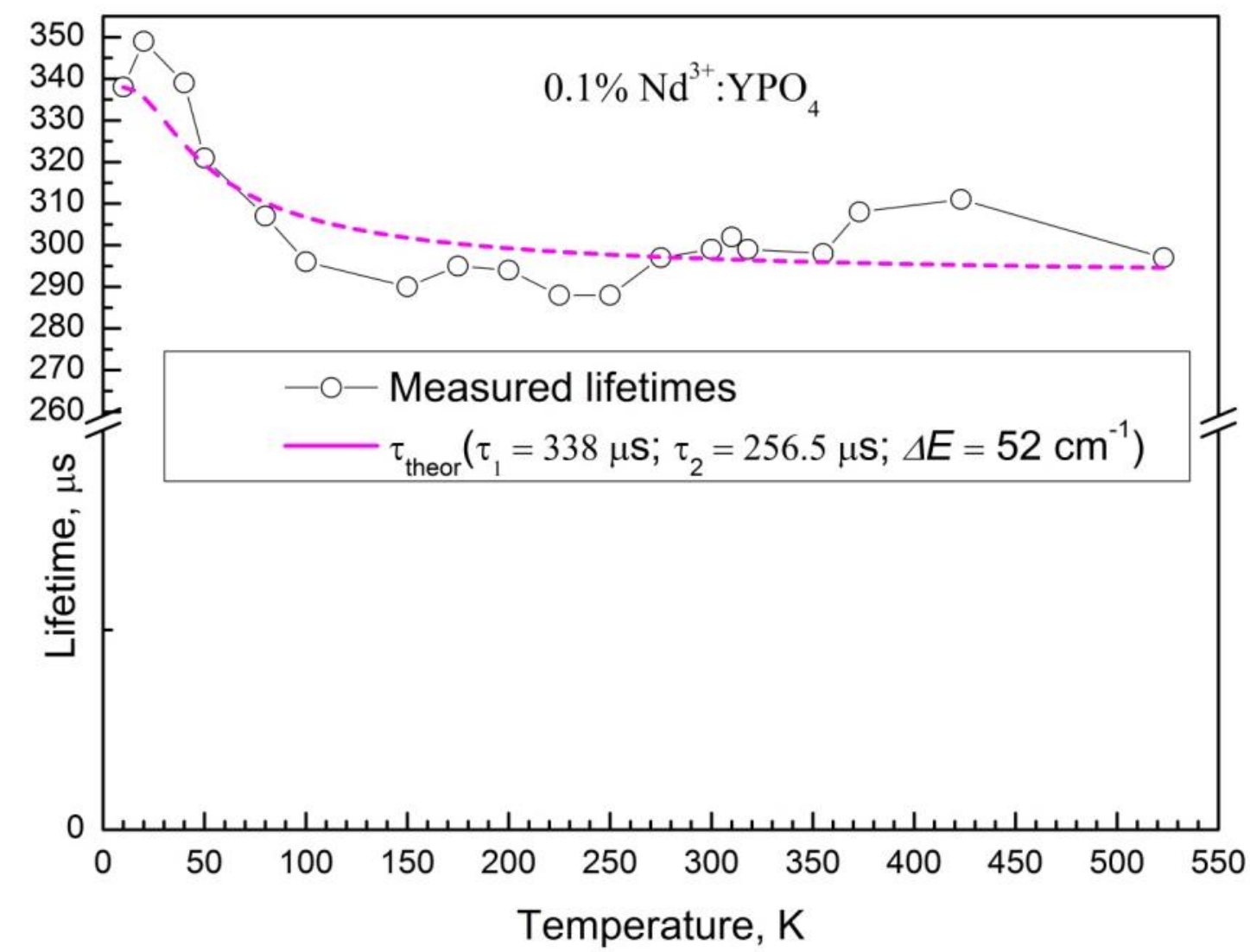

Fig. 12 Temperature dependence of the measured lifetime of the ${ }^{4} \mathrm{~F}_{3 / 2}$ level of the $\mathrm{Nd}^{3+}$ ion in the $0.1 \% \mathrm{Nd}^{3+}: \mathrm{YPO}_{4}$ nanoparticles (hollow circles). Theoretical dependence (1) - (4) for fixed $\tau_{1}$ and $\tau_{2}$ values (magenta dashed line), $\tau_{1}=338 \mu$ s is measured at $10 \mathrm{~K}, \tau_{2}$ is adjustable parameter.

\subsection{The Florescence Intensity Ratio (FIR) method}

As already mentioned the high-frequency phonon crystalline matrixes $\mathrm{YAG}$ and $\mathrm{YPO}_{4}$ makes possible to populate the crystal field levels of the ${ }^{4} \mathrm{~F}_{5 / 2}$ level in physiological temperature range exciting the ${ }^{4} \mathrm{~F}_{3 / 2}$ metastable level, thereby increasing the sensitivity of FIR method employing electronic levels with energy difference $\Delta E>1000 \mathrm{~cm}^{-1}$. The measured fluorescence spectra for the $1 \% \mathrm{Nd}^{3+}$ : YAG microparticles at $315 \mathrm{~K}$ at $808 \mathrm{~nm}$ laser excitation (Fig. 13a) and $0.1 \% \mathrm{Nd}^{3+}: \mathrm{YPO}_{4}$ (Fig. 13b) nanoparticles at $315 \mathrm{~K}$ at $805 \mathrm{~nm}$ laser excitation allow to choose optical transitions between crystal-field levels of two manifolds with minimal overlap of their fluorescent spectral lines with the spectral lines of other transitions. For $1 \%$ $\mathrm{Nd}^{3+}$ : YAG this will be line $I_{2}$ which corresponds to the ${ }^{4} \mathrm{~F}_{5 / 2}+{ }^{2} \mathrm{H}_{9 / 2}(4) \rightarrow{ }^{4} \mathrm{I}_{9 / 2}$ (5) transition and line $I_{1}$, which corresponds to the ${ }^{4} \mathrm{~F}_{3 / 2}(1) \rightarrow{ }^{4} \mathrm{I}_{9 / 2}(5)$ transition. For the $0.1 \% \mathrm{Nd}^{3+}: \mathrm{YPO}_{4}$ nanoparticles the lines 1 and 2 correspond to the ${ }^{4} \mathrm{~F}_{5 / 2}+{ }^{2} \mathrm{H}_{9 / 2}(1) \rightarrow{ }^{4} \mathrm{I}_{9 / 2}(5)$ and ${ }^{4} \mathrm{~F}_{3 / 2}(1) \rightarrow$ ${ }^{4} I_{9 / 2}$ (5) transitions, respectively (Fig. 3). 

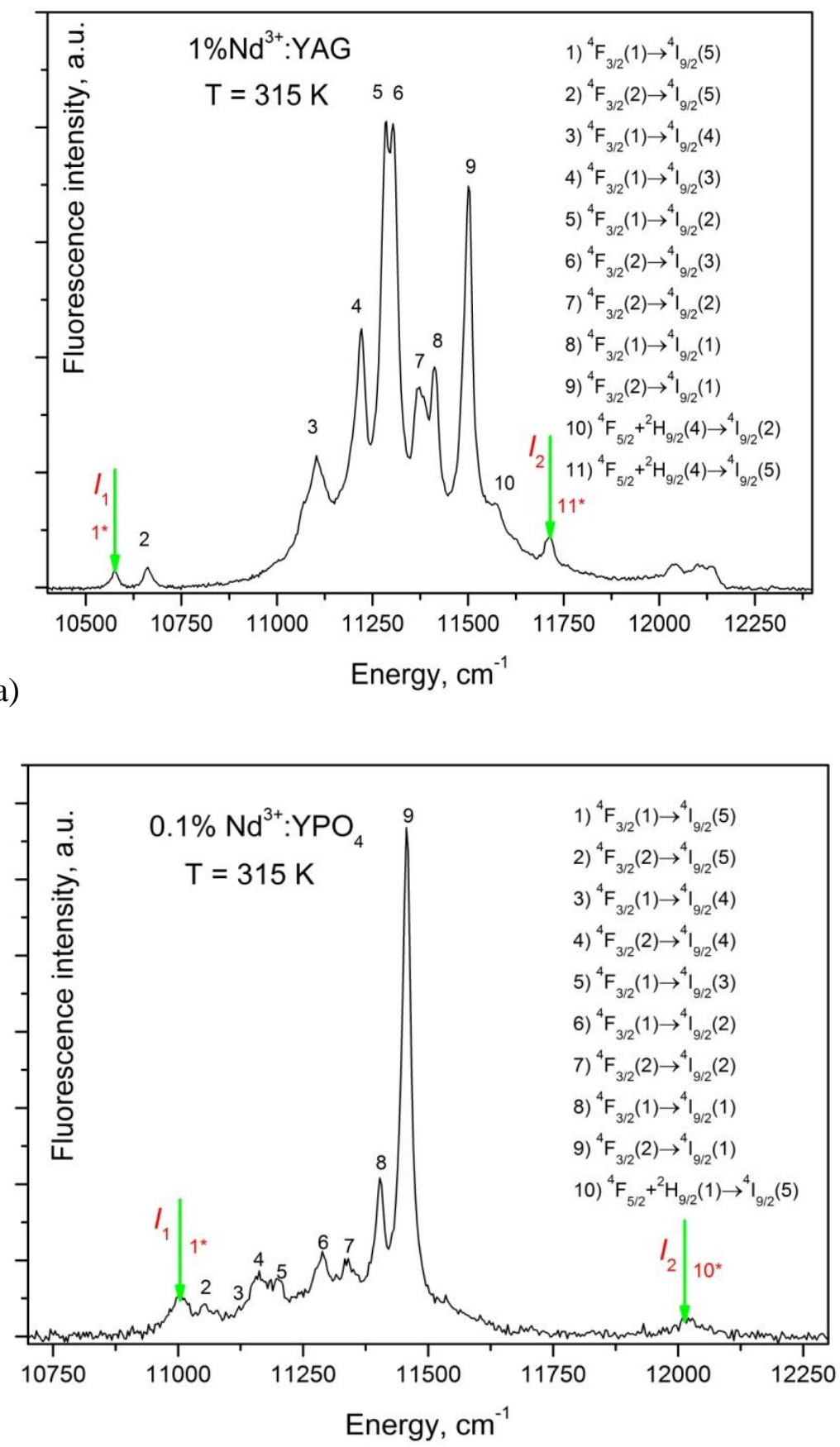

b)

Fig. 13 Fluorescence spectrum of $\mathrm{Nd}^{3+}$ ion in NIR spectral range for the a) $1 \% \mathrm{Nd}^{3+}$ YAG microparticles at $315 \mathrm{~K}$ at $808 \mathrm{~nm}$ laser excitation; b) the $0.1 \% \mathrm{Nd}^{3+}: \mathrm{YPO}_{4}$ nanoparticles at $315 \mathrm{~K}$ at $805 \mathrm{~nm}$ laser excitation. Marked are the spectral lines and optical transitions used for FIR temperature measurement.

Areas under these spectral lines, which overlap with other spectral lines, were determined by multiplication by 2 of the value of area under the nonoverlapping half part of the spectral line. The measured temperature dependencies of the ratio for chosen spectral lines $I_{2} / I_{1}$ is closely 
follow Eq. (10) with $\Delta E=1148 \mathrm{~cm}^{-1}$ for the $1 \% \mathrm{Nd}^{3+} \mathrm{YAG}$ powder (sensitivity $1.8 \% \mathrm{~K}^{-1}$ ) (Fig. 14a) and $\Delta E=1015 \mathrm{~cm}^{-1}$ for the $0.1 \% \mathrm{Nd}^{3+} \mathrm{YPO}_{4}$ nanoparticles (sensitivity $1.6 \%{ }^{\circ} \mathrm{K}^{-1}$ ) (Fig. 14b). The $\Delta E$ values correspond to the energy difference between chosen Stark levels of excited manifolds. The higher the $A_{2} / A_{1}$ ratio reflects the higher line strengths of the transitions from the ${ }^{4} \mathrm{~F}_{5 / 2}$ manifold comparing with those from the ${ }^{4} \mathrm{~F}_{3 / 2}$ manifold. Boltzmann distribution of the population for chosen Stark levels of neighboring manifolds is set due to wide phonon spectrum of both crystalline matrices, allowing for the fast picosecond singlephonon relaxation of optical excitation from the ${ }^{4} \mathrm{~F}_{5 / 2}$ to the ${ }^{4} \mathrm{~F}_{3 / 2}$ manifold and back. For the $\mathrm{Nd}^{3+}: \mathrm{YPO}_{4}$ crystal the value of maximal phonon is $1100 \mathrm{~cm}^{-1}$ - significantly larger than the energy gap $\left(\Delta E=962 \mathrm{~cm}^{-1}\right)$ between the ${ }^{4} \mathrm{~F}_{5 / 2}(1)$ and ${ }^{4} \mathrm{~F}_{3 / 2}$ (2) Stark levels. For the $\mathrm{Nd}^{3+}$ : YAG crystal this value $\left(850 \mathrm{~cm}^{-1}\right)$ is comparable with the energy gap $\left(\Delta E=858 \mathrm{~cm}^{-1}\right)$ between these levels. Nevertheless, in physiological temperature range significant deviation of experimentally established $I_{2} / I_{1}$ ratio around the theoretical curve (Fig. 14) was observed. This does not allow measuring the temperature with desired accuracy, despite the steep slope of the theoretical curve, due to weak intensity of the stand-alone spectral lines. It is expected that this technical problem can be solved if one takes the pulsed laser with more stable pulse amplitude together with long accumulation time of each spectrum. 


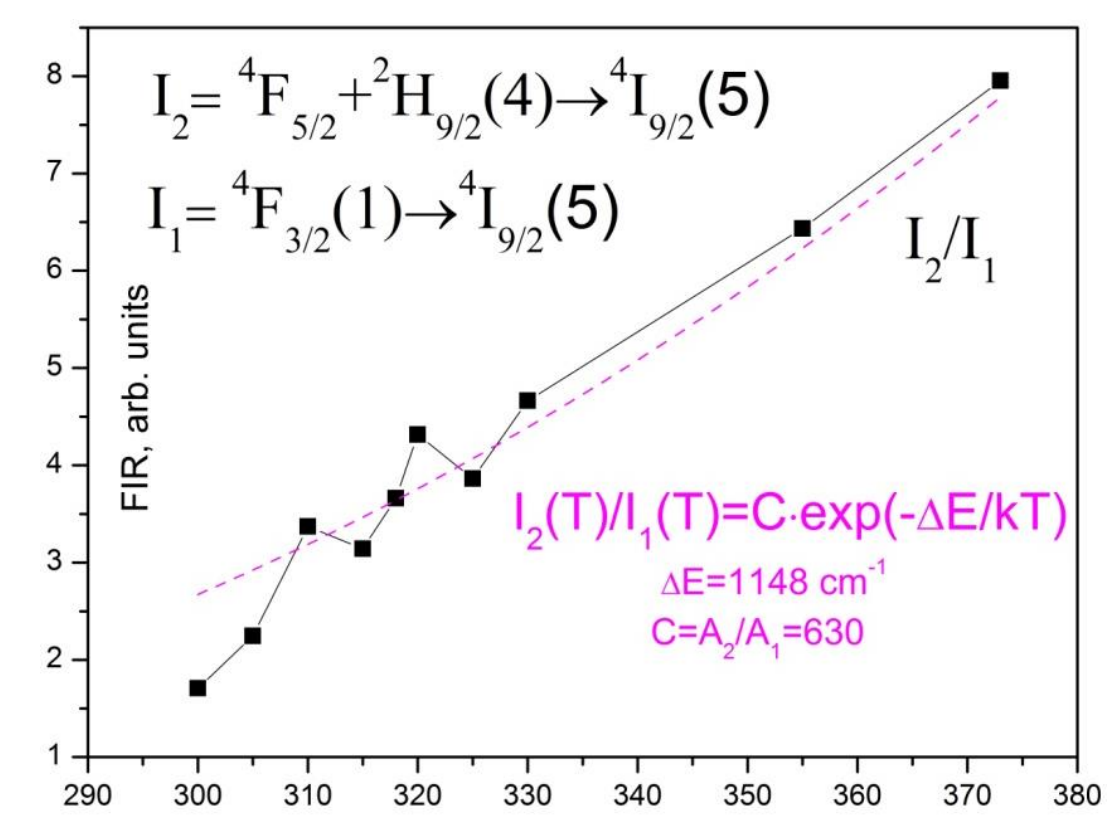

a)

$$
\mathrm{T}, \mathrm{K}
$$

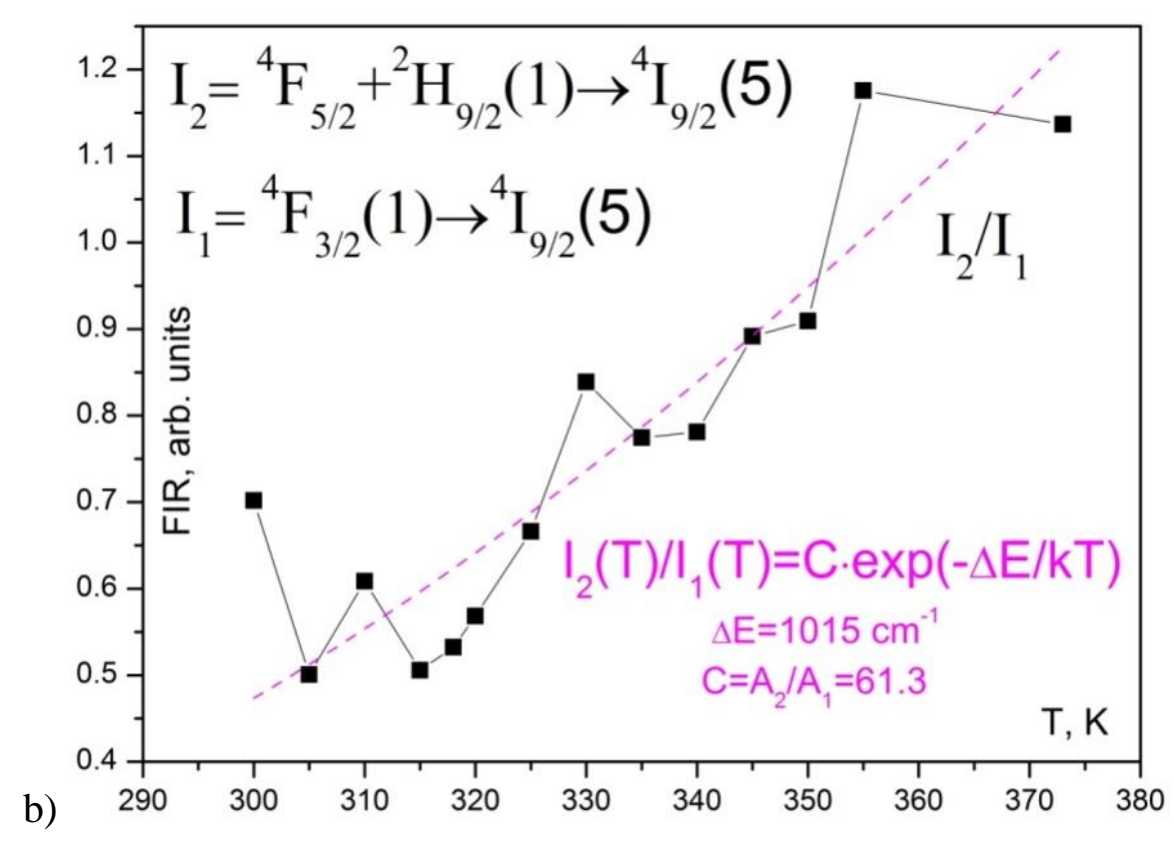

Fig. 14 Experimentally measured temperature dependence of ratio of areas under spectral lines: a) $\mathrm{I}_{2}\left({ }^{4} \mathrm{~F}_{5 / 2}+{ }^{2} \mathrm{H}_{9 / 2}(4) \rightarrow{ }^{4} \mathrm{I}_{9 / 2}(5)\right)$ and $\mathrm{I}_{1}\left({ }^{4} \mathrm{~F}_{3 / 2}(1) \rightarrow{ }^{4} \mathrm{I}_{9 / 2}(5)\right)$ in the $1 \% \mathrm{Nd}^{3+} \mathrm{YAG}$ microparticles (black squares); b) $\mathrm{I}_{2}\left({ }^{4} \mathrm{~F}_{5 / 2}+{ }^{2} \mathrm{H}_{9 / 2}(1) \rightarrow{ }^{4} \mathrm{I}_{9 / 2}(5)\right)$ and $\mathrm{I}_{1}\left({ }^{4} \mathrm{~F}_{3 / 2}(1) \rightarrow{ }^{4} \mathrm{I}_{9 / 2}\right.$ (5)) in the $0.1 \% \mathrm{Nd}^{3+} \mathrm{YPO}_{4}$ nanoparticles (black squares); and approximation using Eq. (10) (magenta dashed lines). 


\section{Conclusion}

As a result the requirements to crystal matrix doped by $\mathrm{RE}^{3+}$ ions may be formulated in order to use it as a real-time operating temperature sensor in NIR spectral range based on the measurement of temperature dependence of fluorescence kinetics. It is necessary to have in the NIR spectral range two nearby spaced manifolds with $\Delta E<800 \mathrm{~cm}^{-1}$, which does not exceed the maximal phonon energy in the crystal to ensure Boltzmann distribution of population over Stark levels of both manifolds. Also a big difference in decay times of spontaneous emission of the levels is required. Both YAG and $\mathrm{YPO}_{4}$ particles doped with $\mathrm{Nd}^{3+}$ are not applicable for temperature measurements in physiological range by fluorescence kinetic method.

Similar demands can be formulated for the fluorescence intensities ratio method (FIR). Additional requirement is the narrow homogeneously broadened fluorescence spectral lines in NIR spectral range. The presence of only one type of optical centers in rare earth ions doped matrix is important for both methods. The $\mathrm{YPO}_{4}$ matrix doped by $\mathrm{Nd}^{3+}$ unlike the YAG matrix partially meets the demands for FIR method. 


\section{Summary}

Two methods for contactless optical temperature measuring - luminescence kinetic and fluorescence intensity ratio (FIR) methods - were introduced with the possible application in the hyperthermal cancer treatment. $\mathrm{Nd}^{3+}$ doped $\mathrm{YAG}$ micro- and $\mathrm{YPO}_{4}$ nanocrystals were taken as the possible candidates and both methods tested on them.

The fluorescence kinetic method experimental results fit good with the theory, but not in the desired temperature range. For the particles used in this work this method works best in the temperatures below $150 \mathrm{~K}$ and not for the physiological temperature range.

The fluorescence intensity ratio (FIR) method looks more promising considering the medical application, but the achieved accuracy was not good enough, despite steep slope of the theoretical curve. The desired accuracy could possibly be reached by using more stable equipment.

The requirements for potential candidates for RE doped crystalline fluroescence kinetic and FIR temperature sensors were formulated. Two nearly spaced manifolds in the NIR spectral range with rather large $\Delta E$ to increase the temperature sensitivity and crystal matrices for doping with wide phonon spectra to ensure Boltzmann distribution of population over Stark levels of both manifolds are needed. Also the presence of only one type of optical centers in $\mathrm{RE}$ ions doped matrix and the narrow homogenously broadened fluorescence spectral lines are important. The kinetic method also requires a big difference in decay times of spontaneous emission from these levels.

The obtained results have been published in a scientific paper (J. Lumin. 183 (2017) 478485). 


\section{Ackownledgements}

My biggest thanks go to my supervisors Yury Orlovskiy and Ilmo Sildos for guiding me trough the problems and experiments not only during the last two years, but also during the bachelor's studies. I am also very grateful to Laurits Puust for helping with the measurements. Special thanks also go to Alexandra Nefedova, Elena Orlovskaya, and Alexander Vanetsev for the synthesis of the particles. 


\section{References}

[1] B. del Rosal, A. P. Delgado, M. Misiak, A. Bednarkiewicz, A. Vanetsev, Y. Orlovskii, D. Jovanovic, M. Dramicanin, U. Rocha, K. Kumar, C. Jacinto, E. Navarro, E. Rodriguez, M. Pedroni, A. Speghini, G. Hirata, I. Martin and D. Jaque, "Neodymium doped nanoparticles for infrared fluorescence bioimaging: the role of the host," no. 118, p. 143104, 2015.

[2] K. Grattan and Z. Zhang, Fiber Optics Fluorescence Thermometry, London: Chapman and Hall, 1995.

[3] D. Wawrzynczyk, A. Bednarkiewicz, M. Nyk, W. Strek and W. Samoc, "Neodymium (III) doped fluoride nanoparticles as non-contact optical temperature sensors," Nanoscale, no. 4, pp. 6959-6961, 2012.

[4] U. Rocha, C. Jacinto da Silva, W. Ferreira Silva, I. Guedes, A. Benayas, L. Martinez, M. Acosta Elias, E. Bovero, J. Gracia Sole, J. Garcia Sole and D. Jaque, "Subtissue thermal sensing based on neodymium-doped $\mathrm{LaF}_{3}$ nanoparticles," ACS Nano, no. 7, pp. 11881199, 2013.

[5] E. Carrasco, B. del Rosal, F. Sanz-Rodriguez, A. Juarranz de la Fuente, P. Haro Gonzales, U. Rocha, K. Kumar, C. Jacinto, J. Garcia Sole and D. Jaque, "Intratumoral thermal reading during photo-thermal therapy by multifunctional fluorescent nanoparticles," Adv. Funct. Mater., pp. 1-12, 2014.

[6] S. Collins, G. Baxter, S. Wade, T. Sun, K. Grattan, Z. Zhang and W. Palmer, "Comparison of fluorescence-based temperature sensor schemes: theoretical analysis and experimental validation," J. Appl. Phys., no. 84, pp. 4649-4654, 1998.

[7] L. Marciniak, K. Prorok, A. Bednarkiewicz, A. Kowalczyk, D. Hreniak and W. Strek, "Water dispersibe $\mathrm{LiNdP}_{4} \mathrm{O}_{12}$ nanocrystals: new multifunctional NIR-NIR luminescent materials for bio-aplications," J. Lumin., no. 76, pp. 144-148, 2016.

[8] L. Merkle and R. Powell, "Energy transfer among $\mathrm{Nd}^{3+}$ ions in garnet crystals," Phys. Rev., no. 20, pp. 75-84, 1979. 
[9] R. Buisson and J. Liu, "Fluorescence quenching of $\mathrm{Nd}^{3+}$ in $\mathrm{LaF}_{3}$ studied by direct measurements on pairs," J. De. Phys, no. 45, pp. 1523-1531, 1984.

[10] S. Fedorenko and A. Burshtein, "Reversible energy quenching and conservation," Chem. Phys, no. 370, pp. 208-214, 2010.

[11] S. Fedorenko and A. Burshtein, "Exciplex formation accompanied with excitation quenching," J. Phys. Chem., no. 114, pp. 4558-4569, 2010.

[12] V. Rai, "A comparative study of FIR and FL based temperature sensing schemes: an example of $\operatorname{Pr}^{3+}, "$ Appl. Phys, no. 87, pp. 323-325, 2007.

[13] E. Samsonova, A. Popov, A. Vanetsev, K. Keevend, E. Orlovskaya, V. Kiisk, S. Lange, U. Joost, K. Kaldvee, U. Mäeorg, N. Glushkov, A. Ryabova, I. Sildos, V. Osiko, V. Loschenov and Y. Orlovskii*, "Energy transfer kinetics probe for $\mathrm{OH}^{-}$quenchers in the $\mathrm{YPO}_{4}: \mathrm{Nd}^{3+}$ nanocrystals suitable for imaging in the biological tissue transparency window," Phys. Chem. Chem. Phys., no. 16, pp. 26806-26815, 2014.

[14] J. Gruber, M. Hills and T. Allik, "Comparative analysis of $\mathrm{Nd}^{3+}\left(4 \mathrm{f}^{3}\right)$ energy levels in four garnet hosts," Phys. Rev. B., no. 41, pp. 7999-8011, 1990.

[15] A. Vanetsev, E. Samsonova, O. Gaitko, K. Keevend, A. Popov, U. Mäeorg, H. Mändar, I. Sildos and Y. Orlovskii, "Phase composition and morphology of nanoparticles of yttrium orthophosphates synthesized by microwave-hydrothermal treatment: the influence of synthetic conditions," J. Alloy. Compd., no. 639, pp. 415-421, 2015.

[16] A. Kaminskii and B. Antipenko, "Multi-level functional diagrams of crystal lasers," Nauka, p. 269 (in Russian), 1989. 


\section{Non-exclusive licence to reproduce thesis and make thesis public}

I, Kaarel Kaldvee,

herewith grant the University of Tartu a free permit (non-exclusive licence) to:

1.1. reproduce, for the purpose of preservation and making available to the public, including for addition to the DSpace digital archives until expiry of the term of validity of the copyright, and

1.2. make available to the public via the web environment of the University of Tartu, including via the DSpace digital archives until expiry of the term of validity of the copyright,

"Approaches to contactless optical thermometer in the NIR spectral range based on $\mathrm{Nd} 3+$ doped crystalline nanoparticles",

supervised by Yury Orlovskiy and Ilmo Sildos,

2. I am aware of the fact that the author retains these rights.

3. I certify that granting the non-exclusive licence does not infringe the intellectual property rights or rights arising from the Personal Data Protection Act.

Tartu, 25.05.2017 